Review

\title{
Assembling Amperometric Biosensors for Clinical Diagnostics
}

\author{
María Soledad Belluzo, María Élida Ribone and Claudia Marina Lagier *
}

Analytical Chemistry Department, Facultad de Ciencias Bioquímicas y Farmacéuticas, Universidad Nacional de Rosario, Suipacha 531, Rosario -2000- Argentina.

* Author to whom correspondence should be addressed. E-mail: clagier@fbioyf.unr.edu.ar

Received: 1 February 2008 / Accepted: 14 February 2008 / Published: 27 February 2008

\begin{abstract}
Clinical diagnosis and disease prevention routinely require the assessment of species determined by chemical analysis. Biosensor technology offers several benefits over conventional diagnostic analysis. They include simplicity of use, specificity for the target analyte, speed to arise to a result, capability for continuous monitoring and multiplexing, together with the potentiality of coupling to low-cost, portable instrumentation. This work focuses on the basic lines of decisions when designing electron-transfer-based biosensors for clinical analysis, with emphasis on the strategies currently used to improve the device performance, the present status of amperometric electrodes for biomedicine, and the trends and challenges envisaged for the near future.
\end{abstract}

Keywords: Biosensor, electrochemical, amperometric, clinical diagnosis

\section{Introduction}

Current methodologies to determine the species that define or identify one particular clinical condition present several drawbacks, even when leading to reliable results. Requirements of previous separative steps, the need to count with highly trained personnel to perform the analysis, its frequent high cost, the circumscription to state-of-the-art laboratories are, among others, the main reasons that have prompt the search for new analytical technology to achieve advantageous clinical diagnostic methods [1]. Biosensors emerge as upbeat technology to face this challenge.

Biosensors have been defined as compact analytical devices that bring together the use of a biological, a biologically-derived or a biomimic element to recognize the analyte. They are closely associated with, or integrated to, a signal conversion unit, the so-called physicochemical transducer, 
which eventually leads to a read-out. The use of biological materials as recognizing elements gives biosensors a remarkable ability to specifically react with the analyte of interest, distinguishing it from structurally similar compounds.

Taking into account the biomolecule that recognizes the target analyte, biosensors can be named as (i) affinity sensors, when the bioreceptor uses non-covalent interactions like antibody-antigen reactions or DNA strand hybridisation, and (ii) catalytic or enzyme sensors, when the analyte is the enzyme substrate, or it can be detected by measuring the signal produced by one substrate or product of the enzymatic reaction involving the analyte. Biosensors are also classified according to the parameter that is measured by the physicochemical transducer of the biological event. Thus, classically biosensors are grouped into optical, electrochemical, acoustic and thermal ones. Considering that electrochemical reactions directly generate an electronic signal, biosensors based on this approach greatly simplifies signal transduction, avoiding expensive equipment requirement.

Among electrochemical biosensors, the oldest ones, which have led to the higher number of readyto-use devices, are based on the monitoring of electron-transfer processes, thus belonging to the amperometric category. This review will centre on this group. The signal of these biosensors is generated by the electron exchange between the biological system in the bioreceptor layer and one electrode. Generally speaking, when using amperometric biosensors, the analyte undergoes, or is involved, in a redox reaction that can be followed by measuring the current in an electrochemical cell. The analyte, or the species involved with it via a (bio)chemical reaction, changes its oxidation state at one electrode. The electron flux is then monitored and is proportional to the amount of the species electrochemically transformed at the electrode. Figure 1 depicts the working principles of an amperometric biosensor.

Figure 1. Scheme depicting the functional principles of an amperometric biosensor.

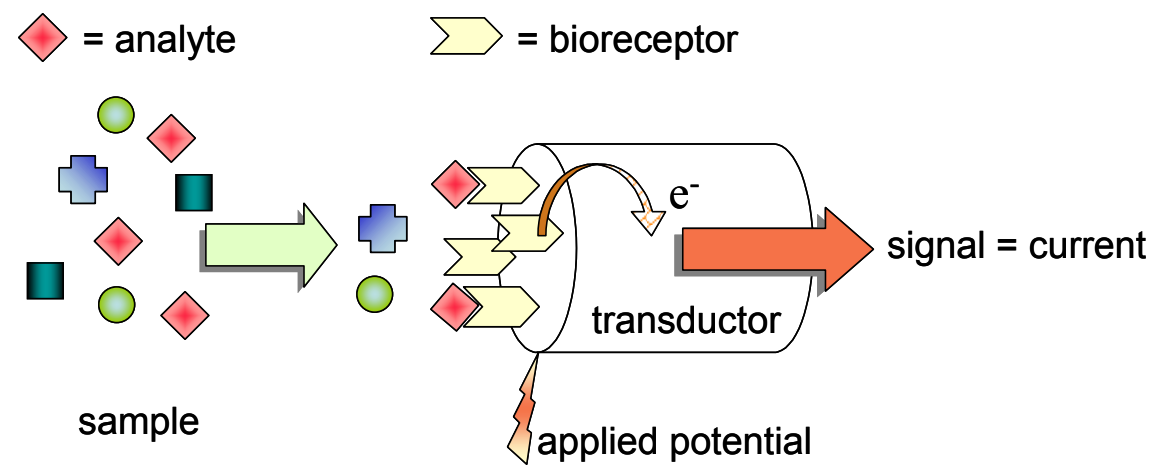

The typical electrochemical technique performed when working with electron-transfer-based biosensors is chronoamperometry, in which the current is measured as a function of time, when the electrode is driven at an appropriate constant potential. Figure $2 A$ shows a standard curve obtained when using an amperometric bioelectrode, in which the current varies upon the addition of a particular compound (e.g. a redox-enzyme substrate) to render a particular product that is electro-transformed at the electrode. The current change registered is proportional to the amount of electro-oxidized/reduced species, which in turn may be directly or inversely proportional to the analyte concentration, depending on the assay format. 
Other electrochemical techniques, based on the electrochemical oxidation/reduction of species directly or indirectly involved in the recognizing biological reaction have been used when dealing with electron-transfer based biosensors. For example, it is possible to follow the amount of a species that is electro-transformed at one electrode by monitoring the time taken to perform such a reaction, when working at constant current, and varying the electrode potential. Fig. $2 B$ depicts a typical curve obtained when carrying out one of these experiments, named potentiometric stripping analysis. The peak area is proportional to the time necessary to electro-transform a species attached to the electrode, which, for example, may be directly proportional to the analyte concentration.

Figure 2. Typical plots of the signals obtained when using electrochemical biosensors based on the amount of electro-transformed species at the electrode by means of (A) chronoamperometry, and (B) potentiometric stripping analysis.

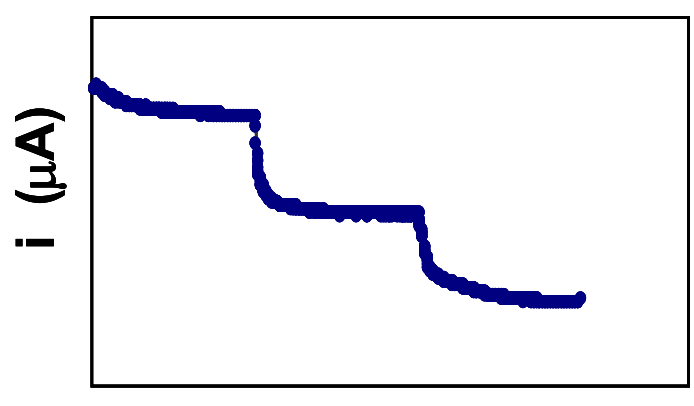

time (s)

A

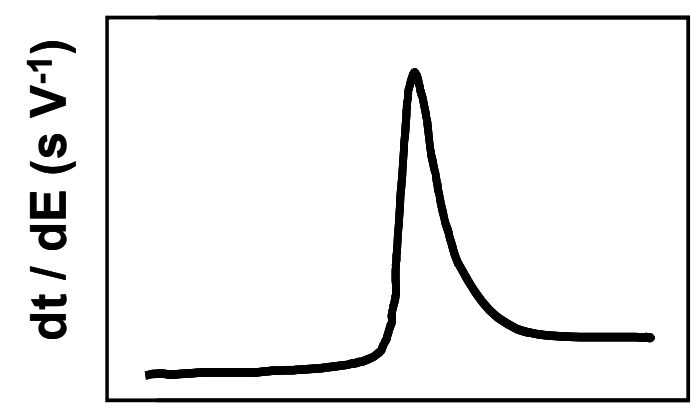

potential (V)

B

Several other electrochemical techniques are also employed when using electron-transfer-based biosensors, such as stripping voltamperometry, differential pulse voltamperometry, coulometry, etc. These methodologies essentially measure parameters related to the amount of electro-transformed material on the electrode as current flows in the cell.

Clark and Lyons presented the precursor of today's biosensors in the early sixties [2], though it was named "the enzyme electrode" rather than a glucose amperometric bioelectrode (Figure 3). The analyte, glucose, diffuses through a dialysis membrane to reach the trapped enzyme, glucose oxidase, which is placed very close to the surface of a platinum electrode. In the presence of the enzyme and oxygen, the analyte produces glucuronic acid and hydrogen peroxide. Monitoring the decrease in oxygen concentration allows to determine the glucose concentration of the medium bathing the outside face of the dialysis membrane. In this case, oxygen is reduced at the metal electrode polarized with a constant potential, and the current flowing in the cell is proportional to the oxygen concentration in the solution. Soon after Clark's proposal, Updike et al. introduced modifications to this first approach to avoid oxygen concentration dependence. They monitored the current flowing in the cell when one of the products of the enzymatic reaction, hydrogen peroxide, was oxidized on an electrode at a convenient potential [3].

Today, Clark's brilliant, pioneering development has evolved, reaching the markets as "bloodglucose, self-testing biosensors". It is routinely used for screening and treating diabetes -an illness 
whose prevalence is $c a$. $4 \%$ of the population in industrialized countries- the equipment being worldwide sold by leader sensor companies [4].

Figure 3. Illustration of Clark's enzyme electrode displaying the reactions occurring at the inner solution containing the enzyme and at the electrode surface.2. SelectivitySpecificity

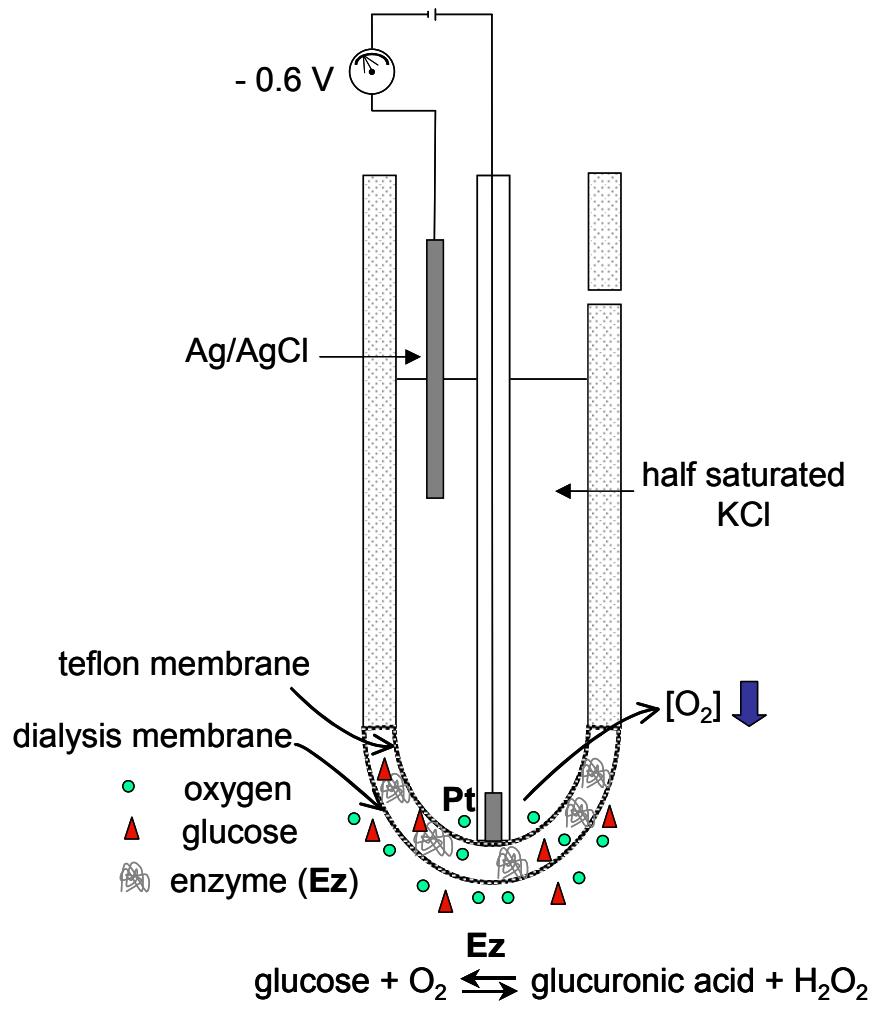

\section{Selectivity-Specificity}

\subsection{Choosing the bioreceptor system}

The bioreceptor layer is responsible for the selectivity/specificity of the device and, in principle, any biological or biologically derived element can be used. Figure 4 summarizes the different bioreceptors we can use to achieve the desired selectivity, according to the nature of the analyte.

It should be noticed that this is the foremost feature of biosensors, since provides the devices the capacity of working without previous treatments of the sample, thus conferring speed to the analysis. The first task when designing a biosensor is to select a suitable bioreceptor system so that the recognition sites interact specifically with the target analyte. This choice depends on the analyte properties and structure, and on the presence of similar interfering substances potentially present in the sample. In clinical-chemical analysis, we deal with biological samples, which display a complex matrix likely carrying interferences. 
Figure 4. Bioreceptors eligible for attachment to the electrode surface.

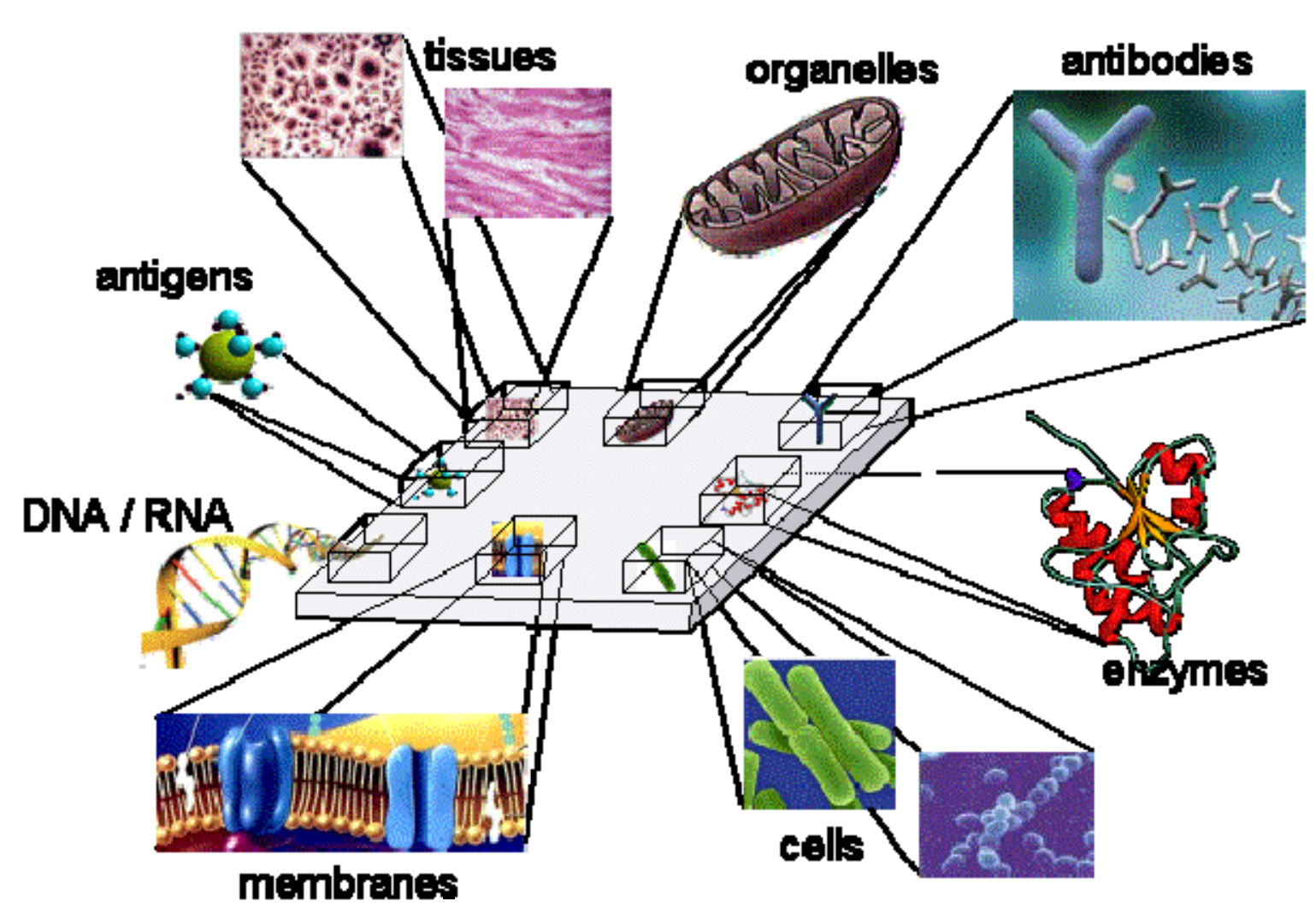

\subsubsection{Enzymes}

The extraordinary specificity displayed by enzymes for their natural substrates makes them the first candidates to be incorporated as the biorecognition element. In principle, we can use redox enzymes that react with the analyte producing products that can be monitored by amperometry via their oxidation/reduction on an electrode, as it was illustrated above with Clark's glucose biosensor. It is worth mentioning here that, when designing enzyme-based biosensors, an important issue is regaining the original oxidation state of the redox active site, so as to keep the enzyme active to react further with its substrate. Generally speaking, it is not feasible to oxidise/reduce the active site of one enzyme by setting directly the electrode potential at any particular value (an exception will be discussed later regarding oriented attachment of bioactive materials in point 3.1). Most of the enzymes used in biosensor technology have their redox centre inside a pocket or at the core of the protein, so that the active site is electrically insulated. This difficulty is commonly tackled by using redox charge mediators, which transport the charge between the enzyme active site and the electrode surface. This subject will be discussed later in section 2.2.

Though it would be desirable to electrochemically detect changes in the enzyme substrate (the analyte) or in one reaction product, most of the analytes of clinical interest are not natural substrates of a redox enzyme. A variety of strategies have been developed to work this problem out, depending on the analyte chemical properties. They are based upon the fact that it is feasible to transform a nonredox reaction into a redox one, which involves an enzyme that changes the oxidation number of the 
species that can be monitored by amperometry. These enzymes are sometimes used as label or reporter of the biological recognition event. Consequently, it has been proposed the use of coupled enzymatic reactions following the one where the analyte participates, to finally produce a species detectable by amperometry. The design below has been proposed by Tsuchida et al. to detect creatine, an important product of protein catabolism, and creatinine, one indicator of kidney function [5]. The coupled reactions are shown in equations 1 to 3 . They ultimately produce hydrogen peroxide, the species that is electrochemically transformed at the electrode to generate an amperometric signal.

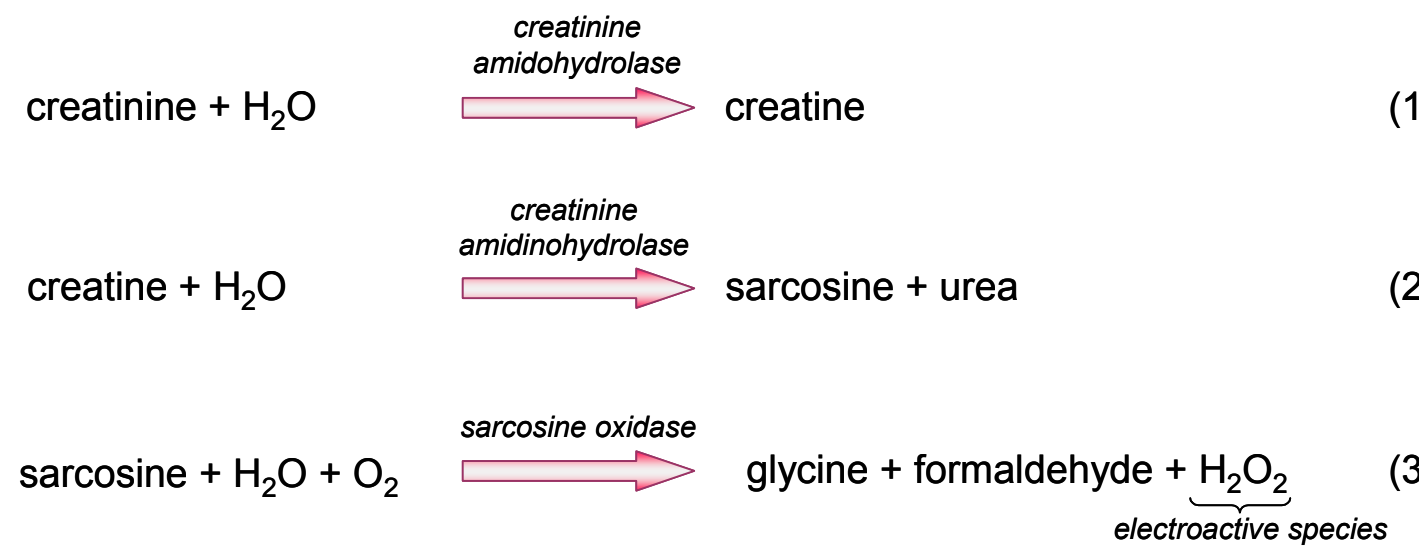

Other biosensors to determine analytes of clinic relevance have been developed, using redox enzymes that allow for the detection of the oxidation or reduction of one product directly or indirectly involved in the enzymatic reaction. They include amperometric biosensors to determine urea [6], lactate [7-9] and pyruvate [10], among others.

\subsubsection{Antibodies, antigens \& aptamers}

When a foreign compound, called antigen (Agn), enters one individual's body, its immunological system generally produces proteins, antibodies (Abs), which bind to such Agn with remarkable specificity. Nowadays, Abs can be either produced by inoculation of the Agn to an immuno-competent individual, or by genetic engineering of bacterial or animal cells [11]. Moreover, currently, it is possible to produce Abs against almost any molecule (analyte), even those unable to stimulate naturally the immune system [12].

Biosensor technology has taken advantage of the high specificity of the Agn-Ab reaction and, since decades, a myriad of research work aimed to clinical-chemistry analysis was carried out [13]. Thus, when the clinical analyte of interest is an Agn, or it can be chemically modified to behave as an Agn, it is possible to use the complementary Abs as capturing molecules in the bioreceptor system. Abs usually interact exclusively with their complementary Agns, thus conferring a remarkable specificity to the device. In this case, the biosensor will be called immunosensor, named after the usage of Abs as bioreceptors.

The use of one enzyme-labelled antigen, added together with the sample carrying the analyte, allows to perform a competitive assay, in a similar way to competitive, enzyme linked immunosorbent assays (ELISA). Figure $5 A$ depicts the competitive immunosensor format, where the target analyte competes with the labelled antigen for the biorecognition sites of the antibody attached to the 
electrode. After rinsing the system, the addition of the redox-enzyme-label substrate generates the product, which is transformed at the electrode, or reacts with one electroactive enzyme co-substrate further added, leading to a detectable current. In this competitive assay, the signal diminishes as the analyte concentration increases.

Figure 5. Scheme depicting different immunoassay formats using amperometric detection. (A) Biosensor to detect an antigen using a competitive immunoassay format, with a redox-enzyme-labelled antigen and the natural substrate of the enzyme, Ez. (B) Biosensor to detect a specific antibody using an indirect immunoassay format.

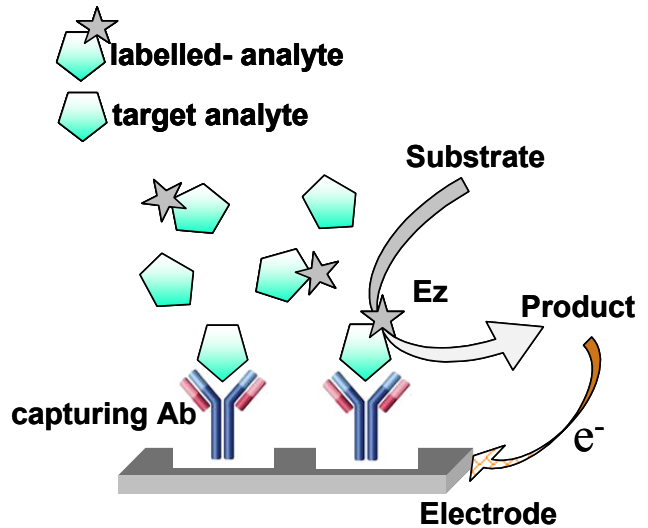

A

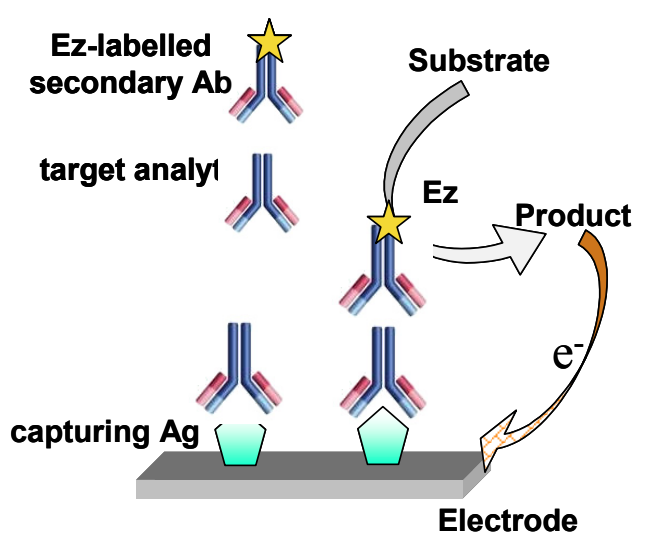

B

Diagnostic electron-transfer-based immunosensors have been reported to detect cancer markers, such as prostate specific antigen [14,15] and carcinoembryonic antigen [16], a pregnancy-indicator hormone, human chorionic gonadotrophine (hCG) [17], the hormone indicative of ovary function, progesterone [18], cholesterol [19], creatinine [20], and auto-antibodies of Type I diabetes [21], among others. The reader is referred to wide-ranging immunosensor reviews such as those listed in references $[13,22,23]$.

When the analyte is an $\mathrm{Ab}$, which is usually the case when diagnosing an infection, another immunological assay scheme can be performed, similar to that used to detect Agns. In this case, the bioreceptor is the Agn, which captures the specific Ab from the sample. A subsequently added redox, enzyme-labelled secondary $\mathrm{Ab}$ towards a particular region of the analyte (e.g. the Fc region of human immunoglobulin G, IgG, see below) will be captured on the surface of the modified electrode. The occurrence of a current once the substrate of the enzyme label is added evidences the presence of the analyte in the sample. In this case, one expects the signal to increase with the analyte concentration. Figure $5 B$ illustrates the working principle of an indirect immunoassay format with amperometric detection. Biosensors using this format have been proposed by our group [24], and by Ferreira et al [25], to detect Chagas' disease, the most serious parasitosis in South America. Other clinically relevant infections, such as those caused by Schistosoma japonicum [26,27] and hantavirus [28], have been detected with this strategy.

Despite the outstanding specificity of the Agn-Ab reaction, sometimes, cross-reactions may occur. False-positive results are generally associated with the occurrence of non-specific Abs, which are often developed by individuals suffering from other diseases. For instance, when a patient is infected with a 
microorganism phylogenetically related with the one whose infection is to be determined, this individual may have produced Abs against orthologous proteins of both infective agents. Therefore, the use of natural proteins of the microorganism as capturing Agn may lead to incorrect results. In these cases, synthetic recombinant proteins can assist to work the problem out. Recombinant proteins are generally synthesized from DNA sequences engineered to encode peptide fragments where the specific regions responsible of cross-reactivity have been excised [29,30]. The use of recombinant DNA machinery to obtain specific, tailor-made proteins, together with biosensor technology, emerges as an auspicious means to achieve ready-to-use devices. They allow not only to obtain the analyteexclusive bioreceptor, but also to simplify their attachment to the electrode surface (see below, item 3.2.). Our group has synthesized such proteins for chagasic infection diagnosis. Results obtained with amperometric biosensors assembled with the new synthetic proteins have been presented in a preliminary work [31]. The recombinant proteins produced allowed not only to obtain a unique analyte-capturing bioreceptor, but also to attach it to the electrode in an oriented manner.

Recently, aptamers have also been used as analyte-capturing species. Aptamers are linear nucleotide sequences, usually of 15- to 40-nucleotide length, undergoing many intramolecular interactions, which wrinkle the oligonucleotide chain. Therefore, aptamers present a three-dimensional shape that confers the molecules the aptitude to interact either strongly or weakly with partner molecules, depending on their structure. The enormous diversity of aptamer conformational structure, which varies with the nucleotide sequence, allows them to be selected according to the strength of interaction with their partner molecule [32,33]. Thus, aptamers can be chosen so as to tightly and selectively bind to target molecules, including among them virtually any kind of analyte, e.g. proteins, lipids, carbohydrates, DNA, etc. [33,34]. Moreover, aptamers are easily synthesised and isolated. They are more stable than, for example, antibodies, allowing to build up robust biosensors that, at variable settings, do not lose their remarkable specificity [35,36]. These are the reasons why, in the lately years, scientists have preferred the use of aptamers as recognizing element when developing biosensors [33,37-43]. Numerous clinically related aptamer-based biosensors have been designed, as for example, one to detect $17 \beta$-estradiol, a hormone indicative of ovary function [44]. Likewise, electron-transferred based aptasensors to determine small molecules like cocaine in biological fluids have been also developed [45], as well as others to determine thrombin [46-48]; thrombin is the main executioner of the coagulation cascade, and its determination in blood is useful to assess the haemostatic status of patients for the diagnosis of coagulation and thrombotic disorders [49]. Another related aptasensor is the one used to determine simultaneously lysozyme and thrombin [50]; serum lysozyme has been proposed to be a marker of chronic inflammatory diseases, such as sarcoidosis, tuberculosis and liver and bowel inflammatory diseases, as well as of leukemia [51]. Extensive and detailed aptamer-based sensor technology is reviewed in references [33,34,42,52].

\subsubsection{Nucleic acids}

Clinical-chemistry analysis often involves the detection of specific nucleotide sequences related to either a particular microorganism, which may be the causal agent of an infection, or DNA mutations that originate genetic diseases, or that are connected with high probability to develop certain type of diseases. Nucleic acid hybridisation is a thermodynamically favoured process, triggered by highly specific base-pairing interactions, where each nucleotide base strongly binds to its complementary 
base through several hydrogen bonds, efficiently sticking the bases together. Accordingly, DNA/RNA strands are excellent applicants to be used as recognizing elements to build up bioreceptor layers.

In the minimal configuration of amperometric DNA- or RNA-based biosensors, a single-stranded (ss-), nucleic acid sequence is anchored to an electrode to capture the analyte, in this case, its complementary DNA or RNA strand. Once the binding partners have met, the event is detected using different approaches, mostly by using an electrochemical reporter of the hybridisation [53-56]. Since the early sixties, Palecek and co-workers have been studying nucleic acids electrochemically [57-59], and have proposed a number of strategies to detect hybridisation [60-62]. A vast literature has been published on DNA hybridisation detection, some of them included in references [63-68]. Clinical applications using DNA-amperometric-based biosensors include devices potentially useful to determine indicators of pathogenic bacteria [69], virus DNA sequence such as that of SARS virus [70], indicators of chronic myelogenous leukemia [71], and acute promyelocytic leukemia [72]. We refer readers to references [73-75], since they are comprehensive reviews dealing with DNA-based biosensors.

The simplest strategy to detect nucleic acid hybridisation relies on monitoring the direct oxidation/reduction of nucleotide bases. For example, the purine base guanine $(\mathrm{G})$, can be oxidised at a particular potential, firstly rendering 7,8-dihydro-8-oxoG (commonly referred to as 8-oxoG), which suffers further oxidation reactions [76-78] (Figure 6A). In principle, the number of $\mathrm{G}$ residues present in the ss- nucleic acid probe will lead to a directly proportional reduction or oxidation signal. The most important drawback that presents this simple method to determine hybridisation is the high background current in the absence of the hybridisation event [75]. It should be considered that the $G$ electrochemical signal diminishes upon base pairing; this has been ascribed to the molecule rigidity gained after hybridisation [79, and references therein], or to steric hindrance that prevents accessibility of the oxidation sites [80]. To overcome this inconvenience, the replace of $\mathrm{G}$ base by inosine, an hypoxantine-derivative nucleoside, proved to be useful [56,64], since its preferential base partner is the same as for G [81]. Therefore, there is a signal increase after pairing of DNA complementary strands, making this a suitable platform to detect the event.

The use of cationic metal complexes that can associate to double-stranded (ds-) DNA stronger than to ss-DNA has been also proposed [53,54]. In this case, small complexes can intercalate between DNA grooves possessing a much higher affinity for the DNA hybridised compared to ss-DNA. The central metal ion can be electrochemically transformed when is close to the electrode surface, and therefore the signal increases as long as hybridisation takes place. A widely used DNA-intercalating metallic complex is $\operatorname{Co}\left(2,2^{\prime}\right.$-bipyridy 1$) 3_{3}{ }^{3+}$. This compound was used to detect the three-base deletion of $\Delta$ F508 DNA sequence, an indicator useful to diagnose cystic fibrosis [54], and the presence of pathogenic Escherischia coli bacteria [53]. Another similar compound, Co(1,10-phenanthroline $)_{3}{ }^{3+}$, was also used to detect DNA sequence of Mycobacterium tuberculosis [82], Cryptosporidium parvum [83], hepatitis $\mathrm{B}$ virus [84], and the human immunodeficiency virus [82,85]. A variety of other intercalating compounds, such as methylen blue [86], daunomycin and aromatic amines [87], have been used to evidence DNA hybridisation. The two latter ones have been applied to detect the gene encoding for apolipoprotein E, a protein involved in familial dysbetalipoproteinemia [87]. Still another strategy taking advantage of labelled-complementary base sequences has proved to be effective to monitor 
DNA hybridisation. Labels include electroactive molecules such as ferrocene derivatives [88] (Figure $6 B$ ) or enzymes (Figure $6 C$ ) [89-91], as well as other redox-derivative compounds [92-95].

Figure 6. DNA-based biosensor arrangements. (A) Direct detection of DNA by electrooxidation of guanine using an electrode poised at a convenient potential. (B) Electrochemical detection of DNA hybridisation using an electrochemical mediator for the oxidation of guanine species, which bounds to the nucleic acid probe, and is afterwards electro-transformed. The signal reduces as the analyte concentration increases. (C) Electrochemical detection of DNA hybridisation using an oligonucleotide modified with a redox enzyme (Ez). The signal increases upon adding the enzyme substrate, once hybridisation took place.

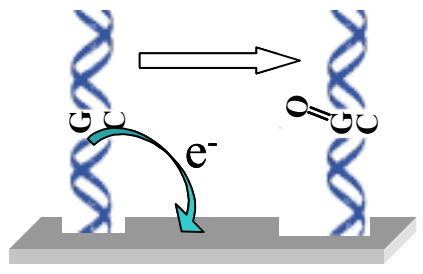

A

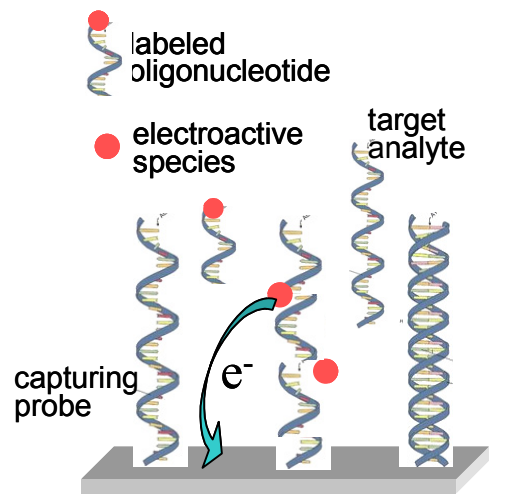

B

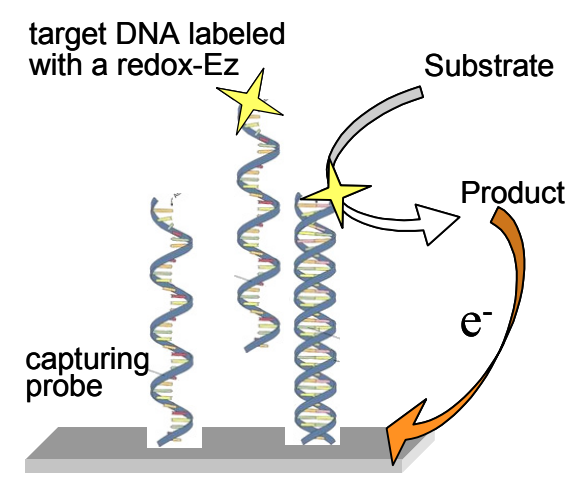

C

A variety of arrays have been reported to rise above the limitations and disadvantages occurring when using DNA-based biosensors, and some of them will be detailed in the following item. For a deeper insight on the subject, we refer the readers to exhaustive reviews, as those referenced next [75,96-98].

\subsection{Avoiding interfering reactions}

Though there are many enzymes whose products can be monitored by amperometry, sometimes complications crop up using the simple model described in point 2.1.1, since other compounds present in the sample matrix may also be transformed on the electrode set at the chosen potential. The same holds true when directly detecting nucleic acid hybridisation via oxidation of G. Certainly, together with the species indicator of the biochemical event taking place at the biorecognition layer, interferences may also be electrochemically oxidised/reduced. For example, when using an amperometric glucose biosensor, which oxidises the hydrogen peroxide produced by the enzymatic reaction shown in Fig. 3, other endogenous substances, e.g. uric and ascorbic acid, gluthatione, cysteine, or exogenous compounds such as manitol, acetaminophene, thiocyanate etc., are also oxidised at the electrode potential [99-103]. In these cases, different strategies have contributed to solving the problem, namely: (i) preventing the interfering compound from occurring in a significant amount nearby the electrode and (ii) working at potentials at which oxidation/reduction of interferences is negligible. 
The simplest proposal to diminish occurrence of non-desired reactions at the electrode is simply by diluting the sample so that the interferences potentially present in the sample are not readily detected. However, this approach is only useful when dealing with highly sensitive devices, such as the one reported to detect uric acid using uricase [104].

Another straightforward method to prevent interferences from reaching the electrode is by using a selectively-permeable membrane, which can operate based on either charge or size properties. One example of the charge rejection approach has been proposed by Zhang et al. [105]. They designed a blood glucose biosensor that uses a Nafion ${ }^{\mathrm{TM}}$ membrane to exclude interfering anions. Examples of interference-excluding membranes based upon size used for glucose amperometric biosensors include the dialysis type ones [100,106], polymers, such as overoxidized polypyrrol [107], polydimethylsiloxane [108], poly(1,2-diaminobenzene) [109], poly(1,3-diaminobenzene/resorcinol) [110,111], poly(o-phenylenediamine) [112] and cellulose acetate [113,114]. In all these cases, polymers allow for permeation of molecules having similar molecular weigh to the analyte, interferences of size larger than the analyte being excluded.

Still another way to remove non-desirable species previously to the detection step is by capturing the analyte, and changing the medium where the electrochemical reaction will take place $[59,60,62,115,116]$. For example, Adam et al. have determined the presence of heavy metals in biological fluids with a biosensor which uses metallothionein, a cystein-rich protein that covalently binds heavy metals via its multiple sulfhydril residues [116,117]. The procedure consists of capturing the heavy metal ions by their interaction with the metallothionein protein, previously adsorbed on a hanging mercury drop electrode. After washing the electrode, a differential pulse voltammetry is performed in a convenient supporting electrolyte to register the corresponding signal $[116,118]$. Magnetic-bead-based biosensors relay on the same principle based on detection of the analyte subsequent to the separative step [119]. In brief, after pairing the target analyte with the biorecognizing element mounted on the beads, the coupled system is magnetically removed from the original sample matrix and transferred to an appropriate interference-free medium for further detection. A number of biosensors have been proposed to detect analytes of clinical interest using this strategy, the device proposed to detect BRCA1 breast cancer gene being one relevant example [120].

The second tactic to avoid interfering reactions consists of working with systems that use electrode potentials at which interferences are not efficiently oxidized/reduced, which can be achieved by using electrochemical mediators [121-125]. Electrochemical mediators commonly used are chemicals displaying a higher kinetic constant for the electron transfer process at the electrode than that of the product selected to monitor the enzymatic reaction. Thus, the electro-transformation of the mediator (med) is favoured, as compared with that of the product of the enzymatic reaction. These compounds usually act as enzyme (Ez) co-substrates mediating the charge transport between the biological recognition element and the electrode, therefore rendering a catalytic cycle, as described in Fig. 7.

It is worth pointing out that when such a catalytic cycle occurs, there is a substantial improvement of the methodology sensitivity due to the recycling of the electrochemically active species, which can be repetitively transformed. A variety of electrochemical mediators, either soluble or directly attached on the electrode, have been used. Most of them deal with the enzyme-electrically-wiring obstacle. Simultaneously, they prevent from electrochemical oxidation/reduction of interferences and, sometimes, they still improve sensitivity. 
Figure 7. Catalytic cycle taking place when using an enzymatic amperometric bioelectrode and an electrochemical mediator that regenerates the original oxidation state of the enzyme redox site.

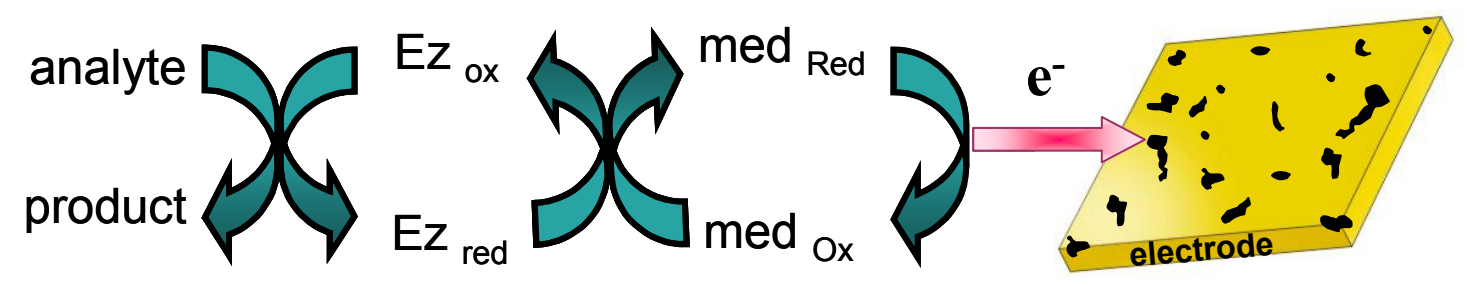

Recently, Alves et al. have described a very interesting mediator for a glucose biosensor [126]. In this case, iron complexes derived from tetra-2-pyridyl-1,4-pyrazine have been mixed with hexacyanoferrate species to render a supramolecular structure that contains Fe(II) and Fe(III) species, inside a highly $\pi$-character network. This polymer exhibits an excellent conductivity together with catalytic activity for $\mathrm{H}_{2} \mathrm{O}_{2}$ electro-reduction, which is displayed by this Prussian Blue-analogue. Therefore, the polymer enables its coupling to a glucose-oxidase enzyme as a redox charge transfer mediator, working at a relatively low potential [126]. Reasonable good performances were also reported for mediators attached on bioelectrodes surface for glucose determination, which include tetracyanoquinodimethane, tetrathiafulvalene, dimethyl ferrocene $[127,128]$, other ferrocene derivatives [129,130], complexes containing Os-bispyridine or derivatives [131-139], methyl viologen or derivatives [133,134], toluidine blue O [135], poly(allylamine)ferrocene [140,141], Ospoly(allylamine) derivatives [142] and poly(aniline) derivatives [143], among others. Moreover, the ExacTECH ${ }^{\mathrm{TM}}$ biosensor from Abbott-Medisense takes advantage of the strategy, using in this case one ferrocene derivative as mediator to monitor glucose blood level [144]. Proposals of clinically-useful biosensors using soluble mediators to detect infection-marker antibodies [24,25], acetylcholine [145], biological oxygen demand [146], as well as other electrode-attached mediators to determine simple molecule analytes, such as glutathione [132], L-alanine and pyruvate [10], lactate [147], and cholesterol [129] accurately have been also reported. Chaubey et al. have published an extensive study on mediators for biosensor applications [148].

Likewise, clever improvements to avoid interference reactions and background currents have been proposed when detecting DNA hybridisation. Some approaches follow the same strategies as for enzymatic biosensors, i.e. physical separation of the analyte from interferences, decrease of working potentials, or both alternatives at the same time. In one of the proposed separative strategies, the DNAcapturing probe is attached to magnetic beads and, once hybridisation is accomplished, the particles are magnetically removed from the medium. The analyte determination proceeds by electron-transferbased electrochemical techniques [60,120].

Once more, considering that the potentials at which the nucleotide bases are electro-transformed are quite extreme, severe interferences from oxidation/reduction of other species present in the sample make necessary additional steps to accurately detect hybridisation [56,59,79,149-151]. That has prompted the development of alternative approaches, as for example, detection of DNA hybridisation by electrocatalytic oxidation of ribose and primary amine residues of nucleotide bases, using copper surfaces [80]. In this approach ss-DNA signal was lower than that generated by ds-DNA, and allowed 
to detect nucleic acids in concentration at the picomolar level [80]. Another option to detect hybridisation is to oxidise $\mathrm{G}$ via a charge transfer mediator, for example the metallic complex $\mathrm{Ru}\left(2,2^{\prime}\right.$ bipyridyl) ${ }^{3+}$, which is easily electro-oxidised at a relatively low potential [152]. This strategy prevents from working at extreme potentials and it has proved success to detect, for example, a sequence of BRCA1 breast cancer gene [153].

Strategies used in biosensor technology to prevent interference reactions from species accompanying the analyte are detailed in reviews $[63,74,75,96]$.

\subsection{Preserving the bioreceptor layer}

Bioreceptors must maintain appropriate biorecognition activity to be used in a biosensing device. Therefore, their structural/conformational integrity must be conserved so as to display a reasonable lifespan. It is obvious that, depending on the complexity of the biorecognition element, the requirements to maintain its integrity will change. In principle, any biological molecule or biomimic assembly capable of recognizing the analyte can be used as a bioreceptor. Table 1 summarizes the main needs to be taken into account according to the biorecognition element used in the bioreceptor layer.

Table 1. Most important requirements to preserve the bioreceptor functionality

\begin{tabular}{|l|l|l|}
\hline \multicolumn{2}{|c|}{$\begin{array}{r}\text { Biorecognition layer (complexity order } \\
\text { increases to the bottom) }\end{array}$} & $\begin{array}{c}\text { Main requests for functional integrity (the } \\
\text { needs usually add up to the bottom) }\end{array}$ \\
\hline \multirow{2}{*}{ Single molecule } & $\begin{array}{l}\text { Aptamer / ion carrier } \\
\text { (ionophore) }\end{array}$ & Appropriate withholding \\
\cline { 2 - 3 } & Antibody / DNA & pH and saline stability \\
\cline { 2 - 3 } & $\begin{array}{l}\text { Enzyme / high molecular } \\
\text { weigh protein }\end{array}$ & $\begin{array}{l}\text { Absence of certain poisoning products } \\
\text { (e.g. heavy metals) }\end{array}$ \\
\cline { 2 - 3 } & Membrane receptor & Mechanic protection \\
\hline Organelle (chloroplast, mitochondrion, etc) & Appropriate osmotic pressure, oxygen \\
\hline Cell & \multirow{2}{*}{ Nutrients } \\
\hline Tissue & Undamaged tissue \\
\hline Organ &
\end{tabular}

From Clark's first biosensor design, in which a dialysis membrane kept the bioreceptor, glucose oxidase, in a solution which preserved its integrity, changes were brought up attempting to improve the stability of the immobilized biorecognition element, and hence the lifetime of the biosensor.

Numerous biosensors in which the recognizing elements are entrapped in passive matrices such as inert polymers, or where the analyte-capturing molecule is cross-linked with other spectator proteins, have been described $[154,155]$. In this line, it has been reported the development of diagnostic biosensors retaining the bioactive molecules via crosslinking with carbodiimide or glutaraldehyde to 
detect, for example, prostate specific antigen [14], Schistosoma japonicum antibody [27], specific chagasic antibodies [25], transferrin [156], and creatinine [157], among others.

Various different bioreceptor-capturing, entrapping polymers used to develop clinically suitable biosensors have been described. Among them, conducting polymers have demonstrated several advantages, such as (i) to give a support to the biologically-active molecule by chemical interactions, either electrostatic, covalent or non-specific interactions, (ii) to allow charge propagation and to "wire" the label (e.g. one redox-enzyme) to the electrode, (iii) to admit the incorporation of redox mediators, and (iv) to enhance mechanical resistance, turning devices more robust. Among these polymers, the pyrrol-based ones have been thoroughly characterised [158-161]. They display excellent properties to be used for biosensor development, since they render appropriate stability and good conductivity [162]. Polypyrrole-based polymers have been successfully used in biosensors to detect urea by means of ureasa entrapped in it [163], and in those where glucose oxidase is immobilised in a polypyrrole hybrid film, displaying very good performances $[126,164,165]$. Other conducting polymers have been used. For example, polyaniline was used to detect antibodies [166], and poly(allylamine) derivatives incorporating a charge transfer mediator have also proved to be efficient for enzyme-based amperometric biosensors $[59,136,167]$. In the last decades, natural polymers, such as chitosan derivatives, have been proposed to immobilize biologically-active species because of their advantageous features such as inertness, biocompatibility, good mechanical resistance, and appropriate film-forming properties [168]. For instance, a biosensor to determine the tumour marker, $\alpha$-1-fetoprotein, whose biorecognition element is an enzyme-labelled antibody, takes advantage of this polymer and a reasonable stability has been reported [169]. A number of other biosensors for clinical applications using modified surfaces with chitosan polymer have been proposed, for example, to detect Schistosoma japonicum antigen [26], dengue virus oligonucleotide sequences [170], and to determine choline; in this latter case the enzyme cholinesterase was cross-linked with glutaraldehyde in a chitosan gel [171]. Reviews focusing on polymers used to assemble amperometric biosensors are referenced in [172-174].

\section{Sensitivity}

One of the most relevant tasks when designing a ready-to-use biosensor is to achieve the needed sensitivity. In all cases, the aimed limit of detection, dynamic range, and sensitivity will depend on the natural sample where the device is to be used. Therefore, the expected range of analyte concentration and the interfering substances potentially present in the sample will largely influence the requirements.

Enhancing any analytical method sensitivity means increasing the signal-to-noise ratio. Two obvious lines of attack are possible: augmenting the signal or diminishing the noise. In electron transfer-based biosensor technology, an enhancement of the signal-to-noise ratio is achieved by increasing the number of electroactive detectable analyte-related species and/or by lowering the interferences that reach the electrode thus giving rise to background current noise. The main strategies used to diminish the background currents produced by interferences have already been addressed in point 2.2. Hence, the "lowering the noise" subject will not be further detailed; we will therefore converge on the topic of signal boosting, which has been faced in the manners described below. 


\subsection{Magnifying the electron-transfer process}

Different ways of achieving the goal of increasing the number of detectable species are possible, two of which are based on magnifying the electron-transfer process, namely:

(i) Recycling the electrochemically-transformed compound. This has already been described above in item 2.2 when considering catalytic enzymatic cycles involving the regeneration of the active-site of the redox enzyme using a charge transfer mediator that is then electrotransformed at the electrode surface (see Fig. 7). Usually, in these cases, the enzyme substrate should be present at excess concentration to keep the enzymatic cycle. The signal that evidences the occurrence of the enzymatic cycle is generally related to the presence (or absence) of the analyte in the sample when performing an indirect (or competitive) immunoassay with electrochemical detection, as described previously in point 2.1.2.

(ii) Amplifying the electron exchange process at the electrode surface using coupled enzymatic systems. In this approach, the analyte (or one analyte-related species), is the substrate of the first enzyme (Ez-1). The analyte and the Ez-1 co-substrate, which is the electro-active species, react with Ez1 to render the products, one of which is the Ez-2 substrate (Fig. 8). Ez-2 reacts with its substrate to regenerate the analyte (or the analyte-related species), thus enabling its recycling to keep consuming Ez-1 co-substrate, this latter one being electrochemically detected. Therefore, even tiny amounts of the analyte can be detected because the consumption of the electroactive species is supported by the cyclic reaction of both enzymes.

Figure 8. Schematic representation of a bi-enzymatic amperometric biosensor. The analyte, $(\hat{W})$ is recycled as long the electroactive species $\)$ is consumed.

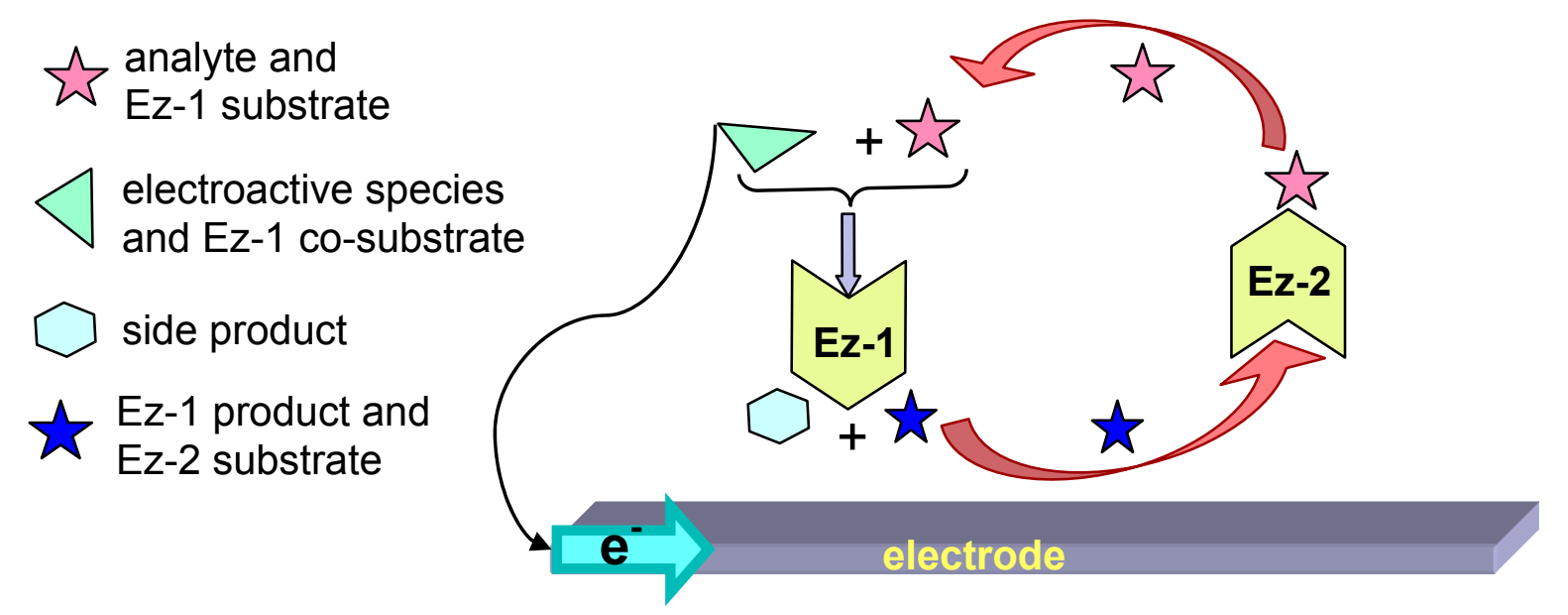

Several examples taking advantage of such bi-enzymatic amplification have been described to detect chatecolamines [175,176], IgG and cocaine [176], among others. This approach was also used to detect successfully lactate via coupling the enzymes lactate oxidase and lactate dehydrogenase, immobilised onto aminopropyl controlled-pore glass [177], or a polyaniline film [178]. The basis of these clinically-relevant biosensors is that one of the products of the first enzymatic reaction is the substrate of the second enzyme, which transforms this product back to the initial species. This cyclical 
conversion allows one electrochemically-active species, acting as co-substrate of the first enzyme, to keep on being consumed, thus multiplying the measured signal.

(iii) Producing additional equivalents of electroactive species, generated by a second enzyme that uses a "side product" of the first enzymatic reaction, which had rendered the first equivalent of electroactive species. An amperometric biosensor using this model was presented by Conrath et al. to detect inorganic phosphate [179]. In the clinical practice, phosphate levels in both blood and urine are determined as indicative of osteopathies, and of parathyroid function [180]. In Conrath's proposal, the first enzyme, maltose phosphorylase, catalyses the reaction between the analyte and maltose, to render $\beta$-D-glucose-1-phosphate and $\alpha$-D-glucose (4). This latter species is further transformed by mutarotase into to $\beta$-D-glucose (5). $\beta$-D-glucose acts as substrate of glucose oxidase to render glucuronic acid and hydrogen peroxide (6), which is the electrochemically detected species. Another enzyme, acid phosphatase, hydrolyses the "side product", glucose-1-phosphate, generating an extra $\beta$-D-glucose (7), which will be also further oxidised according to (6), thus releasing the analyte, phosphate, which can be recycled again.

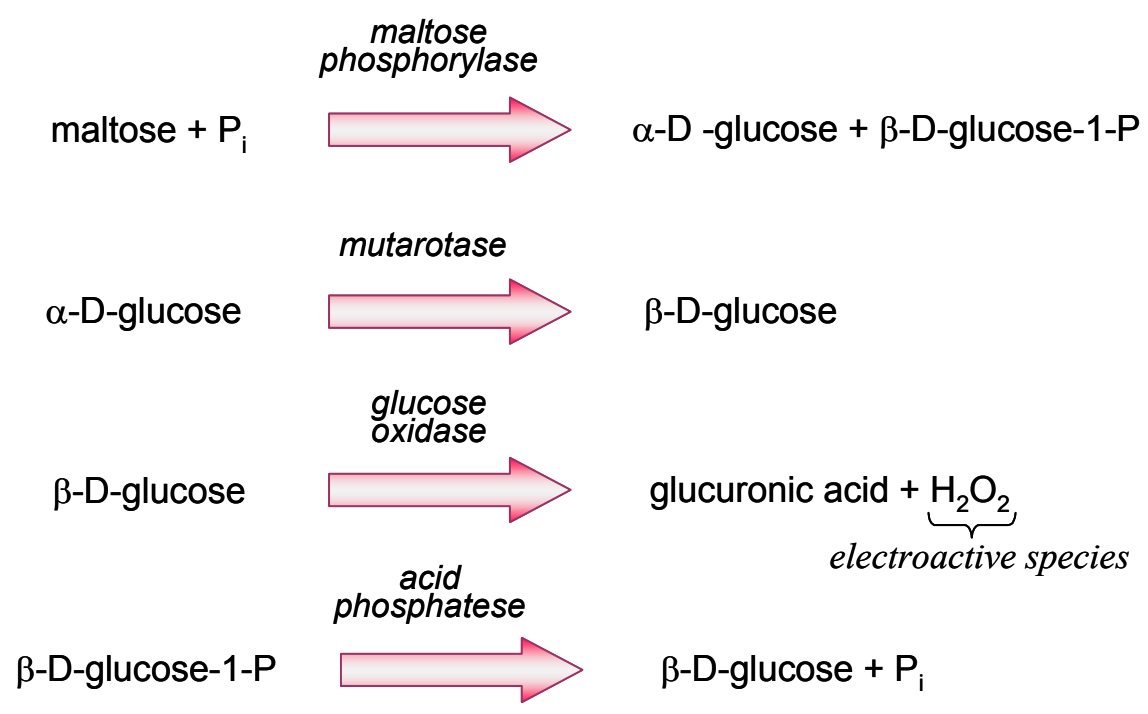

In this interesting example, the signal is not only amplified by the extra amount of substrate rendered by the acid phosphatase using a "side product", but also by recycling the analyte [179].

\subsection{Increasing the number of biorecognition species}

The obvious tactic to raise the amount of the electrochemically-detectable species is enlarging the number of biologically-active molecules in the biorecognition layer, so as to make the analytecapturing step more efficient. Self-assembled monolayers have proved to be useful in biosensor design but, many times, these structures do not offer the desired signal-to-noise ratio and, therefore, it has been proposed to use multilayer systems. Caruso et al. have demonstrated that the signal can be increased using devices with stratified-analogue structure where polymer layers are alternated with layers of the antibody, the analyte being the complementary antigen [181,182]. In a similar way, it has been shown signal enhancement when building up a layer-by-layer, organized supramolecular structure, comprised of a redox polymer and an enzyme-labelled antibody [137,167,183]. In both 
cases, the basic principle is that the electrochemical response obtained is proportional to the amount of the analyte-related species captured.

Sometimes, a more precise control over surface density of biomolecules to prevent molecular aggregation, or to conduct their attachment in a favourable orientation, leads to improved biosensor performances. Calixarene derivatives have been proposed as linking structures to conduct effective protein immobilization [184]. In one proposal, the calixarene structure has thiol residues which link to the gold surface and, at the opposite side, a crownether structure remains exposed to further link the analyte-capturing biomolecule [185]. Thus, enhanced protein binding was achieved by modifying gold electrodes with calixarene-derived monolayers.

Proper oriented attachment is crucial when the bioreactive species comprises a specific IgG antibody. IgG is a Y-shaped molecule, whose specific antigen-binding sites are located at the end of the "arms", the so-called Fab region; the remaining extremity of the molecule, i.e. its base, is named Fc region. When self-assembling IgG-based immunoelectrodes, IgG molecules attach randomly to the surface, and only a fraction of them are useful to capture the analyte. In these cases, it is desired that the IgG Fab region is favourably oriented so as to prevent blockage of the binding sites to effectively capture the antigen. Early studies dealing with this issue were performed by Caruso et al. [186]. They demonstrated that electrodes whose surface had been modified with protein A, a molecule that displays high affinity for the Fc region of $\mathrm{IgG}$, increased the further-immobilized IgG molecule, correctly oriented to react with its target analyte [186]. Using the oriented-linking principle to attach the bioreactive molecules, it has been possible to build an electron-transfer based biosensor to detect Staphilococcal enterotoxin B [187]. Moreover, recent studies on biosensors to determine thrombin have demonstrated the critical importance on the immobilization step. The work demonstrates that the efficiency to capture the analyte was enhanced when using streptavidin-biotine interactions to favourably orient the bioreceptor attachment [48]. In line with this, our group has reported preliminary results on one biosensor to detect specific chagasic antibodies whose capturing antigen is a genetically modified protein tailored to react oriented with a carbodiimide-activated surface. The device has shown sensitivity enhancement as compared with biosensors assembled with the same antigen recognition sites, but without the selective, oriented attachment onto the activated surface [31]. Additionally, we could enhance not only the sensitivity but also the selectivity of the method as mentioned above in item 2.1.2.

Recently, nanotechnology has emerged as the "star" to achieve the signal-augmentation task. Indeed, the last decade has witnessed the blooming of biosensor technology involving nanomatter [188-191]. The problem is once more tackled by boosting the number of available active sites to interact with the analyte.

Nanomatter is composed of unique functional materials that display incomparable characteristics related with their shape, structure and size (in the order of 1 to $100 \mathrm{~nm}$ scale) [192]. According to their shape, nanomaterials have been classified into nanowires, nanotubes, nanobelts, nanosprings, nanorods and nanoparticles. In connection with biosensors, among the most outstanding features of nanomaterials are their mechanical strength, their efficient and tuneable electron-transport properties, and their high surface area per volume unit [188]. Directly related with their arrangement, electrontransfer process may be largely influenced by charge diminution or accumulation when taking place in a linear, one-dimension (1-D) structure, as for example, in a nanowire. This does not occur in a 2-D 
structure, such as a virtually planar film. When charge transport occurs in a 2-D structure, electrons can be transferred along different conducting roads, even those that circumvent high or low charge density sites. On the other hand, charge transport in nanowires or nanotubes takes place along the line direction, which is the only path available to transfer electrons. This makes these materials competent to give a response upon perturbations from even a few molecules interacting along the line $[188,193]$. Together with this exceptional susceptibility, and in relation to their high surface-to-volume ratio, nanomaterials offer massive number of sites that can be chemically functionalized. When building electrochemical biosensors, this is translated into a plethora of analyte-interacting sites, thus leading to sensitivity enhancement [188-190].

Depending on the nanostructure composition, several strategies have been proposed to modify the nanomaterial surface, generally proceeding according to the methods already established to develop amperometric biosensors. For example, gold nanoparticles were utilized to develop amperometric biosensors to determine IgG [194], hepatitis B surface antigen [195], and lactate [196], among others. Also gold nanotubes have been modified by alkylthiols to which the enzymes of interest had been attached, thus allowing to determine clinically-relevant analytes [197,198]. The enzymes glucoseoxidase and horseradish-peroxidase, commonly used in clinical biosensor technology, have been covalently linked via activation using carbodiimide, or cross-linking it with glutaraldehide [197,198]. The same principle described above when addressing DNA-biosensor technology, in which metallic electrochemical mediators are used to catalyse $\mathrm{G}$ oxidation, has been also used together with functionalized carbon nanotubes (CNT) to detect the hybridisation event. In this case, the detection limit has been lowered to a few attomoles of the analyte [199]. In another example, the already known discriminative properties of Nafion were combined with the recently-demonstrated hydrogen peroxide catalytic properties of CNT [200]. Thus, Wang et al. have reported that it is feasible to suspend CNT in Nafion solutions, the resulting system showing a dramatic decrease of the overpotential for hydrogen peroxide detection; this provides an improved way towards glucose-oxidase biosensors development [200]. It was also demonstrated the feasibility of designing biosensors useful for clinical chemistry analysis by means of CNT-based pastes biocomposite bioelectrodes [201].

The vast number of recently published work involving nanotechnology to design electrochemically-based biosensors demonstrates that this is one of the most fertile fields of research, and that prospects of biosensors useful for clinical diagnosis will be closely related to it. Thorough reviews on this subject are referenced as [188-190,193,202].

\section{Simplicity of use and packaging}

Protocols to be followed when using biosensors should be as simple as possible, so that the device operation results amenable. This is an important feature to bear in mind, since it is usually related to market acceptability.

Generally, the use of classical amperometric-based biosensors requires a number of consecutive steps. Clever solutions to shorten procedures have been reported, for example, by performing separation-free immunoassays [203]. These amperometric biosensors relay on a self-assembled antibody monolayer attached onto a double-sided microporus gold electrode. The layout allows spatial separation between the excess of conjugate in solution and the conjugate bound to the bioreceptor 
layer. Therefore, the proposal has advantages with respect to common ELISA, such as fewer steps and the possibility of performing it in the field [204-206].

Label-free biosensors have also become attractive because of their easiness of use. An outstanding approach has been proposed to determine glucose using glucose-oxidase directly "plugged" to the electrode taking advantage of the controlled electron transference through a CNT [207]. The electrode surface was thiolated, and CNTs were covalently aligned using carbodiimide. The enzyme co-factor was also covalently attached at the opposite end of the nanotubes by using carbodiimide. Finally, the apoenzyme was added, the enzyme was effectively reconstituted and glucose transformation into glucuronic acid was then monitored by amperometry, without using any charge transfer mediator [207]. The reader is referred to a recent review on contacting redox proteins using nanotechnology [208]. In another example, hCG was detected using an immunosensor where Abs against this pregnancy-indicator hormone had been oriented attached by means of protein A. hCG concentration was determined measuring the peak current by square wave stripping voltammetry [209]. Additional applications where label-free biosensors were used can be found in the following references [210-214]. Some of them also present renewable devices, another attractive characteristic aimed to lower the cost of the analysis [212].

In addition, the need to move classical analytical tools into miniaturised devices is easily understood, since the latter ones reduce production and operative costs, apart from attenuating environmental impact. Certainly, the possibility of working in the micro-scale allows to use few microliters of reagents, thus making the operation not only cheaper than when using macro/semimicro scale techniques but also less hazardous [215]. The development of clinically-useful biosensors is moving in that direction due to the fact that the reactant requirements are definitely lower than those of classical methodologies. Micro-scale biosensor devices intrinsically have the ability to react with the analyte and generate a measurable response within the same compact body. A good example is the enzymatic biosensor to detect lactate in saliva in a one-step analysis [216]. The system consists of a silicon wafer where a three-electrode cell is built up. Lactate oxidase is entrapped in an agarose gel placed inside a cavity of the silicon chip. The sample diffuses through the pores, and the product of the enzymatic reaction is detected by amperometry [216].

\section{Future directions}

Even though it is desirable to perform the clinical-chemistry analysis in only one step, sometimes the complexity of the sample carrying the analyte and/or its low concentration make us to face with challenging problems. The progress in microfluidic systems allows for integration of different steps to perform the analysis within a single package [217-219]. The steps may include pretreatments, such as filtration, pre-concentration, extraction, derivatization, reaction and, eventually, analyte detection [220]. The so-called lab-on-a-chip technology has emerged as a gifted tool to cope with these real complex samples [217,221]. At the present time, schemes of biosensors coupled to layouts allowing for separative or pre-concentration steps are promising tools to deal with complex-matrix samples [217]. A novel approach has been reported to detect nucleic acids, which illustrates the matter [222]. The device consists of an ultramicroelectrode array where a glass chip is integrated with poly(dimethylsiloxane) channels. An electroactive compound is carried inside liposomes labeled with one ss-DNA tag. Another additional ss-DNA probe is linked to superparamagnetic beads, the target ss- 
DNA being complimentary to both tags. A magnet captures the liposome-analyte-magnetic bead sandwich inside the microfluidic channel, where the electroactive compound is released to be further electrochemically detected [222]. This appliance is a good example of compact ultra-micro systems that combine microfluidics and amperometric based biosensors.

Considering that samples for clinical analysis are largely complex, the above-mentioned appliances are foreseen as the next-generation diagnostic devices [23]. Furthermore, these devices can help even when the problem magnifies because not only the sample but also the disease is complex, which is the case of cancer. This illness may be shuttled by a variety of genetic or/and epigentic changes directly acting on the overgrowth capacity of the cells. Up to these days, there is not a unique, specific tumor marker that could be used as indicator of every existing type of cancer. Numerous alterations on oncogenes or tumor-suppresor genes may be associated with cancer development, in such a way that using a single DNA-genosensor may not allow to diagnose the illness. Indeed, apart from DNA changes related to cancer, many other alterations occur during the disease. For example, multiple variations evidenced as over/under expression of certain proteins or mRNA, lead to an enormous number of different biomarkers that can be associated with the more than 200 types of cancer [223,224]. In such a complex scenario, new tools are necessary to perform simultaneous measurements of various analytes that generate multiple signals at the same time. Biosensors for clinical-chemistry analysis have demonstrated to move towards simplifying the analytical procedures with the advantage of multiplexing capability [23]. It is worth mentioning that this possibility can provide the physician important information that will facilitate early cancer detection. This is a critical point for treating the disease at an early stage, a fact that leads to improved prognosis [23,224]. Additionally, it is also important to monitor the anti-tumoral drug concentration in the patient's fluids as a means to adjust the doses necessary to keep effectiveness of the treatment. In connection with this, it has been proposed a biosensor to detect one of the most used chemotherapy medication, cisplatin [225], using the same strategy already mentioned to determine heavy metal concentration in human fluids [116]. Petrlova's et al. work [225], is another example in reference to biosensor technology as a powerful option to get clinically relevant information.

Up to now, most of clinical analysis is carried out in centralised laboratories were high-technology equipment is available, and trained personnel perform the determinations under almost ideal conditions, i.e. temperature control, use of standard solutions and calibrators, etc. Nevertheless, the actual trend in clinical practice to monitor the health-state of the patient is directed towards point-ofcare screening analysis, and household equipment [226-228]. Moreover, most underserved population in developing countries do not access to state-of-the-art diagnostic methods [229]. The emergence of technology that changes sophisticated diagnostic tools by low-cost, accurate and portable systems seems to be an urgent need, making possible to reach even rural people who hardly move to Health Centres [24]. Nowadays, the development of such new technology seems reachable. Research on biosensors, biotechnology, nanomaterials and microfluidics forefront technology, interacting synergistically, is expected to greatly help to achieve this goal.

\section{Acknowledgements}

CONICET (PIP N ${ }^{\circ}$ 5303) and ANPCyT (PICTR2002-00057) are acknowledged. M.S.Belluzo acknowledges a fellowship from CONICET. The authors gratefully thank Dr. Marcelo Gabriel Roma 
(Instituto de Fisiología Experimental, IFISE, CONICET) for fruitful suggestions, critical comments and thoroughly revision of this work.

\section{References and Notes}

1. Luppa, P. B.; Sokoll, L. J.; Chan, D. W. Immunosensors: principles and applications to clinical chemistry. Clin. Chim. Acta 2001, 314, 1-26.

2. Clark, Jr L. C.; Lyons, C. Electrode systems for continuous monitoring in cardiovascular surgery. Ann. NY. Acad. Sci. 1962,102, 29-45.

3. Updike, S. J.; Hicks, G. P. The enzyme electrode. Nature 1967, 214, 986-988.

4. a) Anon: News and Market Update. Biosens. Bioelectron. 1998, 13, I-II; b) Newman, J.; Turner, A. P. F. Home blood glucose biosensors: a commercial perspective. Biosens. Bioelectron. 2005, 20, 2435-2453.

5. Tsuchida, T.; Yoda, K. Multi-enzyme membrane electrodes for determination of creatinine and creatine in serum. Clin. Chem. 1983, 29, 51-55.

6. Senda, M.; Yamamoto, Y. Urea biosensor based on amperometric ammonium ion electrode. . 1993, 5, 775-779.

7. Kost, G. J.; Nguyen, T. H.; Tang, Z. Whole blood glucose and lactate: trilayer biosensors, drug interference, metabolism and practice guidelines. Arch. Pathol. Lab. Med. 2000, 124, 1128-1134.

8. Aduen, J.; Bernstein, W. K.; Khastgir, T.; Miller, J.; Kerzner, R.; Bhatiani, A.; Lustgarten, J.; Bassin, A. S.; Davison L.; Chernow, B. The use and clinical importance of a substrate specific electrode for rapid determination of blood lactate concentrations. Jama-J. Am. Med. Assoc. 1994, 272, 1678-1685.

9. Durliat, H.; Causserand, C.; Comtat, M. Bienzyme amperometric lactate-specific electrode. Anal. Chim. Acta 1990, 231, 309-311.

10. Gilis, M.; Durliat, H.; Comtat, M. Amperometric biosensors for L-alanine and pyruvate assays in biological fluids. Anal. Chim. Acta 1997, 355, 235-240.

11. Rasmussen, S. K.; Rasmussen, L. K.; Weilguny, D.; Tolstrup, A. B. Manufacture of recombinant polyclonal antibodies. Biotechnol. Lett. 2007, 9, 845-852.

12. de StGroth, S. F.; Scheidegger, D. Production of monoclonal antibodies: strategy and tactics. $J$. Immunol. Methods 1980, 35, 1-21.

13. Morgan, C. L.; Newman, D. J.; Price, C. P. Immunosensors: technology and opportunities in laboratory medicine. Clin. Chem. 1996, 42, 192-209.

14. Sarkar, P.; Pal, P.; Ghosh, D.; Setford S.; Tothill, I. Amperometric biosensors for detection of the prostate cancer marker (PSA). Int. J. Pharm. 2002, 238, 1-9.

15. Okuno, J.; Maehashi, K.; Kerman, K.; Takamura, Y.; Matsumoto, K.; Tamiya, E. Label-free immunosensor for prostate-specific antigen based on single-walled carbon nanotube arraymodified microelectrodes. Biosens Bioelectron. 2006, 22, 2377-2381.

16. Tang, H.; Chen, J.; Nie, L.; Kuang, Y.; Yao, S. A label-free electrochemical immunoassay for carcinoembryonic antigen (CEA) based on gold nanoparticles (AuNPs) and nonconductive polymer film. Biosens Bioelectron. 2007, 22, 1061-1067. 
17. Aizawa, M.; Morioka, A.; Suzuki, S.; Nagamura, Y. Enzyme immunosensor III. Amperometric determination of human choriogonadotropin by membrane bound antibody. Anal. Biochem. 1979, 94, 22-28.

18. Pemberton, R. M.; Hart, J. P.; Mottran, T. T. An electrochemical immunosensor for milk progesterone using continuous flow system. Biosens. Bioelectron. 2001, 16, 715-723.

19. Gilmartin, M. A. T.; Hart, J. P. Fabrication and characterization of a screen printed, disposable amperometric cholesterol biosensor. Analyst 1994, 119, 2331-2336.

20. Benkert, A.; Scheller, F. W.; Schoessler, W.; Micheel, B.; Warsinke, Axel. Size Exclusion Redox-Labeled Immunoassay (SERI): A New Format for Homogeneous Amperometric Creatinine Determination. 2000, 12, 1318-1321.

21. Lee, S. H.; Lee, H.; Park, J. S.; Choi, H.; Han, K.Y.; Seo, H. S.; Ahn, K.Y.; Han, S. S.; Cho, Y.; Lee, K. H.; Lee, J. A novel approach to ultrasensitive diagnosis using supramolecular protein nanoparticles. FASEB J. 2007, 21, 1324-1334.

22. Luppa, P. B.; Sokoll, L. J.; Chan, D. W. Immunosensors-principles and applications to clinical chemistry. Clin. Chim. Acta 2001, 314, 1-26.

23. Wang, J. Electrochemical biosensors: Towards point-of-care cancer diagnostics. Biosen. Bioelctron. 2006, 21, 1887-1892.

24. Ribone, M. E.; Belluzo, M. S.; Pagani, D.; Macipar, I. S.; Lagier, C. M. Amperometric bioelectrode for specific human immunoglobulin $\mathrm{G}$ determination: optimization of the method to diagnose American trypanosomiasis. Anal. Biochem. 2006, 350, 61-70.

25. Ferreira, A. A. P.; Colli, W.; Da Costa, P. I.; Yamanaka, H. Immunosensor for the diagnosis of Chagas' disease. Biosens. Bioelectron. 2005, 21, 175-181

26. Lei, C.-X.; Gong, F.-C.; Shen, G.-L.; Yu, R.-Q. Amperometric immunosensor for Schistosoma japonicum antigen using antibodies loaded on a nano-Au monolayer modified chitosan-entrapped carbon paste electrode. Sens. Actuat. B-Chem 2003, 96, 582-588.

27. Zhou, Y.-M.; Wu, Z.-Y.; Shen, G.-L.; Yu, R.-Q. An amperometric immunosensor based on Nafion-modified electrode for the determination of Schistosoma japonicum antibody. Sens. Actuat. B-Chem. 2003, 89, 292-298

28. Krishnan, R.; Ghindilis, A. L.; Atanasov, P.; Wilkins, E.; Montoya, J.; Koster, F. T. Fast amperometric immunoassay for hantavirus infection. . 1996, 8, 1131-1134

29. Aguirre, S.; Silber, A. M.; Brito, M. E. F.; Ribone, M. E.; Lagier, C. M.; Mancipar, I. S. Design, Construction and Evaluation of a Specific Chimeric Antigen to Diagnose Chagasic Infection. $J$. Clin. Microbiol. 2006, 44, 1043-1046.

30. Marcipar, I. S.; Roodveldt, C; Corradi, G.; Cabeza, M. L.; Brito, M. E. F.; Floeter Winter, L. M.; Marcipar, A. J.; Silber, A. M. Use of full-length recombinant calflagin and its c fragment for improvement of diagnosis of Trypanosoma cruzi infection. J. Clin. Microbiol. 2005, 43, 54985503.

31. Belluzo, M. S.; Ribone, M. E.; Caussone, C.; Marcipar I. S.; Lagier, C. M. Oriented Protein Attachment Onto Gold Electrodes To Perform A Highly Sensitive And Selective Immunoassay With Amperometric Detection. 11th Int. Conf. Electroanal. ESEAC 2006; P1-021.

32. Ellington, A. D.; Szostak, J. W. In vitro selection of RNA molecules that bind specific ligands. Nature 1990, 346, 818-822. 
33. Tombelli S, Minunni M, Mascini M. Analytical applications of aptamers. Biosens Bioelectron. 2005, 20, 2424-34.

34. Willner, I.; Zayats, M. Electronic Aptamer-Based Sensors. Angew. Chem. Int. Edit. 2007, 46, 6408-6418.

35. Jayasena, S. D. Aptamers: An Emerging Class of Molecules That Rival Antibodies in Diagnostics. Clin. Chem. 1999, 45, 1628-1650.

36. Luzi, E.; Minunni, M.; Tombelli, S.; Mascini, M. New trends in affinity sensing: Aptamers for ligand binding. Trends Anal. Chem. 2003, 22, 810-818.

37. Hesselberth, J.; Robertson, M. P.; Jhaveri, S.; Ellington, A. D. In vitro selection of nucleic acids for diagnostic applications. J Biotechnol. 2000, 74, 15-25.

38. O'Suvillan, C. K. Aptasensors: the future of biosensing?. Anal. Bioanal. Chem. 2002, 372, 44-48.

39. McCauley, T. G.; Hamaguchi, N.; Stanton, M. Aptamer-based biosensor arrays for detection and quantification of biological macromolecules. Anal. Biochem. 2003, 319, 244-250.

40. Xu, D.; Xu, D.; Yu, X.; Liu, Z.; He, W.; Ma, Z. Label-Free Electrochemical Detection for Aptamer-Based Array Electrodes. Anal. Chem. 2005, 77, 5107-5113.

41. Ikebukuro, K.; Kiyohara, C.; Sode, K. Novel electrochemical sensor system for protein using the aptamers in sandwich manner. Biosens. Bioelectron. 2005, 20, 2168-2172.

42. Tombelli, S.; Minunni, M.; Mascini, M. Aptamers-based assays for diagnostics, environmental and food analysis. Biomol. Eng. 2007, 24, 191-200.

43. Jiang, T.; Minunni, M.; Mascini, M. Towards fast and inexpensive molecular diagnostic: the case of TP53. Clin. Chim. Acta. 2004, 343, 45-60.

44. Kim, Y. S.; Jung, H. S.; Matsuura, T.; Lee, H. Y.; Kawai, T.; Gu, M. B. Electrochemical detection of 17ß-estradiol using DNA aptamer immobilized gold electrode chip. Biosens. Bioelectron. 2007, 22, 2525-2531.

45. Baker, B. R.; Lai, R. Y.; Wood, M. C. S.; Doctor, E. H.; Heeger, A. J.; Plaxco, K. W. An Electronic Aptamer-Based Small-Molecule Sensor for the Rapid, Label-Free Detection of Cocaine in Adulterated Samples and Biological Fluids. J. Am. Chem. Soc. 2006, 128, 3138-3139.

46. Radi, A. E.; Acero Sanchez, J. L.; Baldrich, E.; O'Sullivan, C.K. Reagentless, Reusable, Ultrasensitive Electrochemical Molecular Beacon Aptasensor. J. Am. Chem. Soc. 2006, 128, $117-$ 124.

47. Mir, M.; Vreeke, M.; Katakis, I. Different Strategies To Develop an Electrochemical Thrombin Aptasensor. Electrochem. Commun. 2006, 8, 505-511.

48. Bini, A.; Minunni, M.; Tombelli, S.; Centi, S.; Mascini, M. Analytical performances of aptamerbased sensing for thrombin detection. Anal. Chem. 2007, 79, 3016-3019.

49. a) Goldsack, N. R.; Chambers, R. C.; Dabbagh, K.; Laurent, G. J. Molecules in focus Thrombin. Int. J. Biochem. Cell. B. 1998, 30, 641-646. b) Wallerstein, R. O. Jr. Laboratory evaluation of a bleeding patient. Western J. Med. 1989, 150, 51-58.

50. Hansen, J. A.; Wang, J.; Kawde, A. -N.; Xiang, Y.; Gothelf, K. V.; Collins, G. QuantumDot/Aptamer-Based Ultrasensitive Multi-Analyte Electrochemical biosensor. J. Am. Chem. Soc. 2006, 128, 2228-2229.

51. Gasior-Chrzan, B. The biological role of lysozyme and its usefulness in clinical practice. Wiad Lek. 1987, 40, 1693-1696. 
52. Navani, N. K.; Li, Y. Nucleic acid aptamers and enzymes as sensors. Curr. Opin. Chem. Biol. 2006, 10, 272-281.

53. Wang, J.; Rivas, G.; Cai, X. Screen-Printed Electrochemical Hybridization DNA Biosensor for the E. Coli Pathogen. . 1997, 9, 395-398.

54. Millan, K. M.; Mikkelsen, S. R. Sequence-Selective Biosensor for DNA Based on Electroactive Hybridization Indicators. Anal. Chem. 1993, 65, 2317-2323.

55. Hashimoto, K.; Ito, K.; Ishimori, Y. Sequence-Specific Gene Detection with a Gold Electrode Modified with DNA Probes and an Electrochemically Active Dye. Anal. Chem. 1994, 66, 38303833 .

56. Thorp, H. H. Cutting out the middleman: DNA biosensors based on electrochemical oxidation. Trends Biotechnol. 1998, 16, 117-121

57. Palecek, E. Oscillographic polarography of highly polymerized deoxyribonucleic acid. Nature 1960, 188, 656-657.

58. Palecek, E. Polarographic techniques in nucleic acid research. Prog. Nucleic Acid Res. Mol. Biol. 1969, 9, 31-73.

59. Palecek, E. Adsorptive transfer stripping voltametry: determination of nanogram quantities of DNA immobilized at the electrode surface. Anal. Biochem. 1988, 170, 421-431.

60. Jelen, F.; Yosypchuk, B.; Kourilova, A.; Novotny L.; Palecek, E. Label-free determination of picogram quantities of DNA by stripping voltammetry with solid copper amalgam or mercury electrodes in the presence of copper. Anal. Chem. 2002, 74, 4788-4793.

61. Palecek, E.; Fojta, M. Detecting DNA Hybridization and Damage. Anal. Chem. 2001, 73, 75A83A.

62. Palecek, E.; Fojta, M.; Jelen, F. New approaches in the development of DNA sensors: hybridization and electrochemical detection of DNA and RNA at two different surfaces. Bioelectrochemistry 2002, 56, 85-90.

63. Gooding, J. J. Electrochemical DNA Hybridization Biosensors. Electroanalysis 2002, 14, 1149 1156.

64. Wang, J.; Rivas, G.; Fernandes, J. R.; Lopez Paz, J. L.; Jiang, M.; Waymire, R. Indicator-free electrochemical DNA hybridization biosensor. Anal. Chim. Acta 1998, 375, 197-203.

65. Domínguez, E.; Rincón, O.; Narváez, A. Electrochemical DNA sensors based on enzyme dendritic architectures: an approach for enhanced sensitivity. Anal. Chem. 2004, 76, 3132-3138.

66. Popovich, N. D.; Eckhardt, A. E.; Mikulecky, J. C.; Napier, M. E.; Thomas, R. S. Electrochemical sensor for detection of unmodified nucleic acids. Talanta 2002, 56, 821-828.

67. Cai, H.; Cao, X.N.; Jiang, Y.; He, P.G.; Fang, Y.Z. Carbon nanotube-enhanced electrochemical DNA biosensor for DNA hybridization detection. Anal. Bioanal. Chem. 2003, 375, 287-293.

68. Wang, J.; Rivas, G.; Cai, X.; Chicharro, M.; Dontha, N.; Luo, D.; Palecek, E.; Nielsen, P. E. Adsorption and detection of peptide nucleic acids at carbon paste electrodes. Electroanalysis 2005, 9, 120-124.

69. Liao, J. C.; Mastali, M.; Gau, V.; Suchard, M. A.: Møller, A. K.; Bruckner, D. A.; Babbitt, J. T.; Li, Y.; Gornbein, J.; Landaw, E. M.; McCabe, E. R. B.; Churchill, B. M.; Haake, D. A. Use of Electrochemical DNA Biosensors for Rapid Molecular Identification of Uropathogens in Clinical Urine Specimens. J Clin Microbiol. 2006, 44, 561-570. 
70. Abad-Valle, P.; Fernández-Abedul, M. T.; Costa-García, A. Genosensor on gold films with enzymatic electrochemical detection of a SARS virus sequence. Biosens. Bioelectron. 2005, 20, 2251-2260.

71. Lin, X.-H.; Wu, P.; Chen, W.; Zhang, Y.-F.; Xia, X.-H. Electrochemical DNA biosensor for the detection of short DNA species of Chronic Myelogenous Leukemia by using methylene blue. Talanta 2007, 72, 468-471.

72. Lin, X. H.; Wan, H. Y.; Zhang, Y. F.; Chen, J. H. Studies of the interaction between Aloe-emodin and DNA and preparation of DNA biosensor for detection of PML-RAR $\alpha$ fusion gene in acute promyelocytic leukemia. Talanta 2008, 74, 944-950.

73. Palecek, E.; Jelen, F. Electrochemistry of nucleic acids and development of DNA sensors. Crit. Rev. Anal. Chem. 2002, 3, 261-270.

74. Wang, J. Electrochemical nucleic acid biosensors. Anal. Chim. Acta 2002, 469, 63-71.

75. Drummond, T. G.; Hill, M. G.; Barton, J. K. Electrochemical DNA sensors. Nat. Biotechnol. 2003, 21, 1192-1199.

76. Ferapontova, E. E. Electrochemistry of guanine and 8-oxoguanine at gold electrodes Electrochim. Acta 2004, 49, 1751-1759.

77. Brooks, S. C.; Richter, M. M. Determination of DNA Bases Using Electrochemistry: A Discovery-Based Experiment. The Chemical Educator 2002, 7, 284-287.

78. Oliveira Brett, A. M.; Piedade, J. A. P.; Serrano, S. H. P. Electrochemical Oxidation of 8Oxoguanine. Electroanalysis 2000, 12, 969-973.

79. Palecek, E. From polarography of DNA to microanalysis with nucleic acid-modifield electrodes. Electroanalysis 1996, 8, 7-14.

80. Singhal, P.; Kuhr, W. G. Ultrasensitive Voltammetric Detection of Underivatized Oligonucleotides and DNA. Anal. Chem. 1997, 69, 4828-4832.

81. Casegreen, S.; Southern, E. Studies on the base pairing properties of deoxyinosine by solid phase hybridisation to oligonucleotides. Nucleic acids Res. 1994, 22, 131-136.

82. Wang, J.; Cai, X.; Rivas, G.; Shiraishi, H.; Dontha, N. Nucleic-acid immobilization, recognition and detection at chronopotentiometric DNA chips. Biosens. Bioelectron. 1997, 12, 587-599.

83. Wang, J.; Rivas, G.; Parrado, C.; Cai, X.; Flair, M. N. Electrochemical biosensor for detecting DNA sequences from the pathogenic protozoan Cryptosporidium parvum. Talanta 1997, 44, 2003-2010.

84. Erdem, A.; Kerman, K.; Meric, B.; Akarca, U. S.; Ozsoz, M. DNA electrochemical biosensor for the detection of short DNA sequences related to the hepatitis B virus. Electroanalysis 1999, 11, 586-588.

85. Wang, J.; Cai, X.; Rivas, G.; Shiraishi, H.; Farias, P. A. M.; Dontha, N. DNA electrochemical biosensor for the detection of short DNA sequences related to the human immunodeficiency virus. Anal. Chem. 1996, 68, 2629-2634.

86. Pan, D.; Zuo, X.; Wan, Y.; Wang, L.; Zhang, J.; Song, S.; Fan, C. Electrochemical Interrogation of Interactions between Surface-Confined DNA and Methylene Blue. Sensors 2007, 7, 26712680.

87. Mascini, M.; Palchetti, I.; Marrazza, G. DNA electrochemical biosensors. Fresenius J Anal Chem. 2001, 369, 15-22. 
88. Liepold, P.; Wieder, H.; Hillebrandt, H.; Friebel, A.; Hartwich, G. DNA-arrays with electrical detection: A label-free low cost technology for routine use in life sciences and diagnostics. Bioelectrochemistry 2005, 67, 143-150.

89. Kerman, K.; Kobayashi, M.; Tamiya, E. Recent trends in electrochemical DNA biosensor technology. Meas. Sci. Technol. 2004, 15, R1-R11

90. Caruana, D. J.; Heller, A. Enzyme-amplified amperometric detection of hybridization and of a single base pair mutation in an 18 -base oligonucleotide on a $7 \mu \mathrm{m}$ diameter microelectrode. $J$. Am. Chem. Soc. 1999, 121, 769-774.

91. Xie, H.; Zhang, C.; Gao, Z. Amperometric detection of nucleic acid at femtomolar levels with a nucleic acid/electrochemical activator bilayer on gold electrode. Anal. Chem. 2004, 76, 16111617.

92. Suye, S.; Matsuura, T.; Kimura, T.; Zheng, H.; Hori, T.; Amano, Y.; Katayama, H. Amperometric DNA sensor using gold electrode modified with polymerized mediator by layerby-layer adsorption. Microelectron. Eng. 2005, 81, 441-447.

93. Zhao, W.; Xu, J. -J.; Chen, H. -Y. Electrochemical Biosensors Based on Layer-by-Layer Assemblies. Electroanalysis 2006, 18, 1737-1748.

94. Xie, H.; Yu, Y. H.; Mao, P. -L.; Gao, Z. Highly sensitive amperometric detection of genomic DNA in animal tissues. Nucleic Acids Res. 2004, 32, 1-7.

95. Fojta, M.; Havran, L.; Billova, S.; Kostecka, P.; Masarik, M.; Kizek, R. Two-Surface Strategy in Electrochemical DNA Hybridization Assays: Detection of Osmium-Labeled Target DNA at Carbon Electrodes. Electroanalysis 2003, 15, 431 - 440.

96. Mikkelsen, S. R. Electrochemical Biosensors for DNA Sequence Detection. Electroanalysis 1996, 8, 15-19.

97. Pividori, M. I.; Merkoci, A.; Alegret, S. Electrochemical genosensor design: immobilisation of oligonucleotides onto transducer surfaces and detection methods. Biosens. Bioelectron. 2000, 15, 291-303.

98. Lucarelli, F.; Marrazza, G.; Turner, A. P. F.; Mascini, M. Carbon and gold electrodes as electrochemical transducers for DNA hybridisation sensors. Biosens. Bioelectron. 2004, 19, 515-530.

99. Siest, G.; Appel, W.; Blijenberg, G. B.; Capolaghi, B.; Galteau, M. M.; Heusghem, C.; Hjelm, M.; Lauer, K. L.; Le Perron, B.; Loppinet, V.; Love, C.; Royer, R. J.; Tognoni, C.; Wilding, P. C. Wilding P. Drug interference in clinical chemistry: studies on ascorbic acid. J. Clin. Chem. Clin. Biochem. 1978, 16, 103-110.

100. Palleschi, G.; Rahni, M. A.; Lubrano, G. J.; Ngeh Nwainbi.; Guilbault, G. G. A study of interferences in glucose measurement in blood by hydrogen peroxide based glucose probes. Anal. Biochem. 1986, 159,114-121.

101. Hills, L.; Azurin, G.; Wang X.; et al. Glutathione as an interferent in near patient whole blood glucose devices. In: Proc. 17th Int. Symp. Int. Fed. Clin. Chem. Omnipress: Madison, Wis, 1998; pp. 207-219.

102. D'Orazio, P.; Parker, B. Interference by the oxidizable pharmaceuticals acetaminophen and dopamine at electrochemical biosensors for blood glucose. Clin. Chem. 1995, 41, S156. 
103. D'Orazio, P. Interference by thiocyanate on electrochemical biosensors for blood glucose. Clin. Chem. 1996, 42, 1124-1126.

104. Hasebe, Y.; Nawa, K.; Ujita, S.; Uchiyama, S. Highly sensitive flow detection of uric acid based on intermediate regeneration of uricase. Analyst 1998, 123, 1775-1780.

105. Zhang, Y.; Hu, Y.; Wilson, G. S.; Moatti-Sirat, D.; Poitout, V.; Reach, G. Elimination of the acetaminophen interference in an implantable glucose sensor. Anal. Chem. 1994, 66, $1183-$ 1188 .

106. Lobel, E.; Rishpon, J. Enzyme electrode for the determination of glucose. Anal. Chem. 1981, 53, 51-53.

107. Palmisano, F.; Rizzi, R.; Centonze D.; Zambonin P. G. Simultaneous monitoring of glucose and lactate by an interference and cross-talk free dual electrode amperometric biosensor based on electropolymerized thin films. Biosens. Bioelectron. 2000, 15, 531-539.

108. Mizutani, F.; Yabuki, S.; Iijima, S. Use of Polydimethylsiloxane for Constructing Amperometric Glucose-Sensing Enzyme Electrode with Low Interference Level. Electroanalysis 2001, 13, 370-374.

109. Sasso, S.; Pierce, R.; Walla, R.; Yacynych, A. Electropolymerized 1,2-diaminobenzene as a means to prevent interferences and fouling and to stabilize immobilized enzymes in electrochemical biosensors. Anal. Chem. 1990, 62, 1111-1117.

110. Reynolds, E. R.; Yacynych, A. M. Direct sensing platinum ultramicrobiosensors for glucose. Biosens. Bioelectron. 1994, 9, 283-293.

111. Geise, R. J.; Adams, J. M.; Barone, N. J.; Yacynych A. M. Electropolymerized films to prevent interferences and electrode fouling in biosensors. Biosens. Bioelectron. 1991, 6, 151-160.

112. Kirwan, S. M.; Rocchitta, G.; McMahon, C. P.; Craig, J. D.; Killoran, S. J.; O’Brien, K. B.; Serra, P. A.; Lowry, J. P.; O’Neill, R. D. Modifications of Poly(o-phenylenediamine) Permselective Layer on Pt-Ir for Biosensor Application in Neurochemical Monitoring. Sensors 2007, 7, 420-437.

113. Vaidya, R.; Wilkins, E. Effect of interference on amperometric glucose biosensors with cellulose acetate membranes. Electroanalysis 1994, 6, 677-682.

114. Gunasingham, H.; Teo, P. Y. T.; Lai, Y.-H.; Tan, S.-G. Chemically modified cellulose acetate membrane for biosensor applications. Biosensors 1989, 4, 349-359.

115. Palecek, E.; Billová, S.; Havran, L.; Kizek, R.; Miculková, A.; Jelen, F. DNA hybridization at microbeads with cathodic stripping voltammetric detection. Talanta 2002, 56, 919-930.

116. Adam, V.; Petrlova, J.; Potesil, D.; Zehnalek, J.; Sures, B.; Trnkova, L.; Jelen, F.; Kizek, R. Study of Metallothionein Modified Electrode Surface Behavior in the Presence of Heavy Metal Ions-Biosensor. Electroanalysis 2005, 17, 1649-1657.

117. Palmiter, R. D. Regulation of metallothionein genes by heavy metals appears to be mediated by a zinc-sensitive inhibitor that interacts with a constitutively active transcription factor, MTF-1. Proc. Natl. Acad. Sci. USA 1994, 91, 1219-1223.

118. Petrlova, J.; Potesil, D.; Mikelova, R.; Blastik, O.; Adam, V.; Trnkova, L.; Jelen, F.; Prusa, R.; Kukacka, J.; Kizek, R. Attomole voltammetric determination of metallothionein. Electrochim. Acta 2006, 51, 5112-5119. 
119. Renault, N. J.; Martelet, C.; Chevolot, Y.; Cloarec, J. P. Biosensors and Bio-Bar Code Assays Based on Biofunctionalized Magnetic Microbeads. Sensors 2007, 7, 589-614.

120. Wang, J.; Kawde, A. B. Amplified label-free electrical detection of DNA hybridazation. Analyst 2002, 127, 383-386.

121. Gorton, G.; Csoregi, E.; Dominguez, E.; Emneus, J.; Jonsson Pettersson, G.; Marko-Varga, G.; Persson, B. Selective detection in flow analysis based on combination of immobilized enzymes and chemically modified electrodes. Anal. Chim. Acta 1991, 250, 203-248.

122. Cass, A. E.; Davis, G.; Francis, G.; Hill, H.; Aston, W.; Higgins, I. J.; Plotkin, E.; Scott, L.; Turner, A. P. Ferrocene-mediated enzyme electrode for amperometric determination of glucose. Anal. Chem. 1984, 56, 667-671.

123. Ivanova, E. V.; Sergeeva, V. S.; Oni, J.; Kurzawa, C.; Ryabov, A. D.; Schuhmann, W. Evaluation of redox mediators for amperometric biosensors: Ru-complex modified carbonpaste/enzyme electrodes. Bioelectrochemistry 2003, 60, 65-71.

124. Ryabov, A. D.; Sukharev, V. S.; Alexandrova, L.; Le Lagadec, R.; Pfeffer, M. New Synthesis and New Bio-Application of Cyclometalated Ruthenium(II) Complexes for Fast Mediated Electron Transfer with Peroxidase and Glucose Oxidase. Inorg. Chem. 2001; 40, 6529-6532.

125. Cardosi, M. F.; Turner, A. P. F. The realisation of electron transfer from biological molecules to electrodes. Biosensors: Fundamentals and Applications; Turner, A., Karube, I., Wilson, G., Eds.; Oxford University Press: New York, 1987; pp 257-75

126. Alves, W. A.; Fiorito, P. A.; Córdoba de Torresi, S. I.; Torresi, R. M. Design of molecular wires based on supramolecular structures for application in glucose biosensors. Biosens. Bioelectron. 2006, 22, 298-305.

127. Pandey, P. C.; Upadhyay, S.; Upadhyay, B. Peroxide biosensors and mediated electrochemical regeneration of redox enzymes. Anal. Biochem. 1997, 252, 136-142.

128. Cass, A. E.; Davis, G.; Francis, G. D.; Hill, H.A.; Aston, W. J.; Higgins, I. J.; Plotkin, E. V.; Scott, L. D.; Turner, A. P. Ferrocene mediated enzyme electrode for amperometric determination of glucose. Anal. Chem. 1984, 56, 667-671.

129. García-Ruiz, E.; Vidal, J. C.; Aramendía, M. T.; Castillo, J. R. Design of an Interference-Free Cholesterol Amperometric Biosensor Based on the Electrosynthesis of Polymeric Films of Diaminonaphthalene Isomers. Electroanalysis 2004, 16, 497-504.

130. Rondeau, A.; Larsson, N.; Boujtita, M.; Gorton, L.; El Murr, N. The synergetic effect of redox mediators and peroxidase in a bienzymatic biosensor for glucose assays in FIA. Analusis 1999, 27, 649-656.

131. Ohara, T. J.; Rajagopalan, R.; Heller, A. "Wired" enzyme electrodes for amperometric determination of glucose or lactate in the presence of interfering substances. Anal. Chem. 1994, 66, 2451-2457.

132. Carano, M.; Cosnier, S.; Kordatos, K.; Marcaccio, M.; Margotti, M.; Paolucci, F.; Prato, M.; Roffia, S. A glutathione amperometric biosensor based on an amphiphilic fullerene redox mediator immobilised within an amphiphilic polypyrrole film. J. Mater. Chem. 2002, 12, 19962000.

133. Ghica, M. E.; Brett, C. M. A. A glucose biosensor using methyl viologen redox mediator on carbon film electrodes. Anal. Chim. Acta 2005, 532, 145-151. 
134. De Lacey, A. L.; Bes, M. T.; Moreno C. G.; Fernandez V. M. Amperometric enzyme electrode for $\mathrm{NADP}^{+}$based on a ferrodoxin-NADP ${ }^{+}$reductase and viologen-modified glassy carbon electrode. J. Electroanal. Chem. 1995, 390, 69-76.

135. Qian, J.; Li, X.; Huang, H. Sol-gel-derived amperometric glucose biosensor based on covalent attachment of toluidine blue $\mathrm{O}$ to carrier. Polym. Advan. Technol. 2003, 14, 207-211.

136. Fei, J.; Wu, Y.; Ji, X.; Wang, J.; Hu, S.; Gao, Z. An Amperometric Biosensor for Glucose Based on Electrodeposited Redox Polymer/Glucose Oxidase Film on a Gold Electrode. Anal. Sci. 2003, 19, 1259-1263.

137. Calvo, E. J.; Battaglini, F.; Danilowicz, C.; Wolosiuk, A.; Otero, M. Layer-by-layer electrostatic deposition of biomolecules on surfaces for molecular recognition, redox mediation and signal generation. Faraday Discuss. Chem. Soc. 2000, 116, 47-65.

138. Danilowicz, C.; Corton, E.; Battaglini, F. Osmium complexes bearing functional groups: Building blocks for integrated chemical systems. J. Electroanal. Chem. 1998, 445, 89-94.

139. Battaglini, F.; Bartlett, P. N.; Wang, J. H. Covalent Attachment of Osmium Complexes to Glucose Oxidase and the Application of the Resulting Modified Enzyme in an Enzyme Switch Responsive to Glucose. Anal. Chem. 2000, 72, 502-509.

140. Pishko, M. V.; Revzin, A.; Simonian, A. L. Mass Transfer in Amperometric Biosensors Based on Nanocomposite Thin Films of Redox Polymers and Oxidoreductases. Sensors 2002, 2, 79-90.

141. Hodak, J.; Etchenique, R.; Calvo, E. J. Layer-by-layer Self Assembley of Glucose Oxidase with a Poly(allylamine)ferrocene Redox Mediator. Langmuir 1997, 13, 2708-2716.

142. Calvo, E. J.; Etchenique, R.; Pietrasanta, L.; Wolosiuk, A.; Danilowicz, C. Layer-by-layer Self Assembly of Glucose Oxidase and Os(bpy)2ClPyCH2NH-Poly(allylamine) Bioelectrode. Anal. Chem. 2001, 73, 1161-1168.

143. Seo, K. D.; Lee, K. P.; Gopalan, A. I.; Chung, S. J.; Lim, Y. T.; Choi, S. H. Horseradish Peroxidase (HRP) Immobilized Poly(aniline-co-m-aminophenol) Film Electrodes-fabrication and Evaluation as Hydrogen Peroxide Sensor. Sensors 2007, 7, 719-729.

144. Wang, J. Electrochemical Glucose Biosensors. Chem. Rev. 2007, 10.1021/cr068123a.

145. Khayyami, M.; Pérez Pita, M. T.; Peña Garcia, N.; Johansson, G.; Danielsson, B.; Larsson, P.-O. Development of an amperometric biosensor based on acetylcholine esterase covalently bound to a new support material. Talanta 1998, 45, 557-563.

146. Pasco, N.; Baronian, K.; Jeffries, C.; Webber, J.; Hay, J. MICREDOX-development of a ferricyanide-mediated rapid biochemical oxygen demand method using an immobilised Proteus vulgaris biocomponent. Biosens. Bioelectron. 2004, 20, 524-532.

147. Gros, P.; Comtat, M. A bioelectrochemical polypyrrole-containing $\mathrm{Fe}(\mathrm{CN})_{6}{ }^{3-}$ interface for the design of a NAD-dependent reagentless biosensor. Biosens. Bioelectron. 2004, 20, 204-210.

148. Chaubey, A.; Malhotra, B. D. Mediated biosensors. Biosens. Bioelectron. 2002, 17, 441-456.

149. Takenaka, S.; Uto, Y.; Kondo, H.; Ihara, T.; Takegi, M. Electrochemically active DNA Probes: Detection of Target DNA Sequences at Femtomole Level by High-Performance Liquid Chromatography with Electrochemical Detection. Anal. Biochem. 1994, 218, 436-443.

150. Fojta, M.; Havran, L.; Kizek, R.; Billová, S. Voltammetric microanalysis of DNA adducts with osmium tetroxide, 2,2'-bipyridine using pyrolytic graphite electrode. Talanta 2002, 56, 867-874 
151. Scheller, F. W.; Wollenberger, U.; Warsinke, A.; Lisdat, F. Research and development in biosensors. Curr. Opin. Biotech. 2001, 12, 35-40.

152. Johnston, D. H.; Glasgow, K. C.; Thorp, H. H. Electrochemical Measurement of the Solvent Accessibility of Nucleobases Using Electron Transfer between DNA and Metal Complexes. $J$. Am. Chem. Soc. 1995, 117, 8933-8938.

153. Koehne, J. E.; Chen, H.; Cassell, A. M.; Ye, Q.; Han, J.; Meyyappan, M.; Li, J. Miniaturized Multiplex Label-Free Electronic Chip for Rapid Nucleic Acid Analysis Based on Carbon Nanotube Nanoelectrode Arrays. Clin. Chem. 2004, 50, 1886-1893.

154. Tijsen, P. Practice and theory of enzyme immunoassays; Elsevier Science Publishers: Amsterdam, 1985; Vol. 15.

155. Guilbault, G. G. Handbook of immobilized enzymes; Marcel-Dekker: New York, 1984.

156. Le, C.-X.; Wu, J.; Wang, H.; Shen, G.-L.; Yu, R.-Q.A new electrochemical immunoassay strategy for detection of transferrin based on electrostatic interaction of natural polymers. Talanta 2004, 63, 469-474.

157. Hsiue, G.-H.; Lu, P.-L.; Chen, J.-C. Multienzyme-immobilized modified polypropylene membrane for an amperometric creatinine biosensor. J. Appl. Polym. Sci. 2004, 92, 3126-3134.

158. Bruckenstein, S.; Brzezinska, K.; Hillman, A. R. EQCM Studies of Polypyrrole Films. 1. Exposure to Aqueous Sodium Tosylate Solutions under Thermodynamically Permselective Conditions. Electrochim. Acta 2000, 45, 3801-3811.

159. Bruckenstein, S.; Brzezinska, K.; Hillman, A. R. EQCM Studies of Polypyrrole Films. 2. Exposure to Aqueous Sodium Tosylate Solutions under Thermodynamically Non-Permselective Conditions. Chem. Phys. 2000, 2, 1221-1229.

160. Varela, H.; Malta, M.; Torresi, R. M. Microgravimetric study of the influence of the solvent on the redox properties of polypyrrol modified electrodes. J. Power Sources 2001, 92, 50-55.

161. Lagier, C. M.; Efimov, I.; Hillman, A. R. Film resonance on acoustic wave devices: the roles of frequency and contacting fluid. Anal. Chem. 2005, 77, 335-343.

162. Li, G.; Wang, Y.; Xu, H. A Hydrogen Peroxide Sensor Prepared by Electropolymerization of Pyrrole Based on Screen-Printed Carbon Paste Electrodes. Sensors 2007, 7, 239-250.

163. Rajesh, Bisht, V.; Takashima, W.; Kaneto, K. An amperometric urea biosensor based on covalent immobilization of urease onto an electrochemically prepared copolymer poly (N-3aminopropyl pyrrole-co-pyrrole) film. Biomaterials 2005, 26, 3683-3690.

164. Fiorito, P.A.; Córdoba de Torresi, S. I. Hybrid nickel hexacyanoferrate/polypyrrole composite as mediator for hydrogen peroxide detection and its application in oxidase-based biosensors. $J$. Electroanal. Chem. 2005, 581, 31-37.

165. Fiorito, P. A.; Brett, C. M. A.; Córdoba de Torresi, S. I. Polypyrrole/copper hexacyanoferrate hybrid as redox mediator for glucose biosensors. Talanta 2006, 69, 403-408.

166. Tahir, Z. M.; Alocilja, E. C.; Grooms, D. L. Indium Tin Oxide-Polyaniline Biosensor: Fabrication and Characterization. Sensors 2007, 7, 1123-1140.

167. Calvo, E. J.; Danilowicz, C.; Lagier, C. M.; Manrique, J.; Otero, M. Characterization of selfassembled redox polymer and antibody molecules on thiolated gold electrodes. Biosens. Bioelectron. 2004, 19,1219-1228. 
168. Wang, G.; Xu, J. J.; Chen H. Y.; Lu, Z. H. Amperometric hydrogen peroxide biosensor with solgel/chitosan network-like film as immobilization matrix. Biosens. Bioelectron. 2003, 18, 335343.

169. Yu, H.; Yan, F.; Dai, Z.; Ju, H. A disposable amperometric immunosensor for $\alpha$-1-fetoprotein based on enzyme-labeled antibody/chitosan-membrane-modified screen-printed carbon electrode. Anal. Biochem. 2004, 331, 98-105.

170. Teles, F. R.; Prazeres, D. M.; Lima-Filho, J. L. Electrochemical Detection of a Dengue-related Oligonucleotide Sequence Using Ferrocenium as a Hybridization Indicator. Sensors 2007, 7, 2510-2518.

171. Yang, M.; Yang, Y.; Yang, Y.; Shen G.; Yu R. Bienzymatic amperometric biosensor for choline based on mediator thionine in situ electropolymerized within a carbon paste electrode. Anal. Biochem. 2004, 334, 127-134.

172. Emr, S. A.; Yacynych, A. M. Use of polymer films in amperometric biosensors. Electroanalysis 1995, 7, 913-923.

173. Palmisano, F.; Zambonin, P. G.; Centonze, D. Amperometric biosensors based on electrosynthesised polymeric films. Fresenius. J Anal Chem. 2000, 366, 586-601.

174. Vidal, J. C.; Garcia-Ruiz, E.; Castillo, J. R. Recent Advances in Electropolymerized Conducting Polymers in Amperometric Biosensors. Microchim. Acta 2003, 143, 93-111.

175. Ghindilis, A. L.; Makower, A.; Bauer, C. G.; Bier, F. F.; Scheller, F. W. Determination of paminophenol and catecholamines at picomolar concentrations based on recycling enzyme amplification. Anal. Chim. Acta 1995, 304, 25-31.

176. Bier, F. F.; Ehrentreich-Forster, E.; Scheller, F. W.; Makower, A.; Eremenko, A.; Wollenberger, U.; Bauer, C. G.; Pfeiffer, D.; Michael, N. Ultrasensitive biosensors. Sensor. Actuat. B-Chem 1996, 33, 5-12.

177. Asouzu, M. U.; Nonidez, W. K.; Ho, M. H. Flow Injection Analysis of L-Lactate with Enzyme Amplification and Amperometric Detection. Anal. Chem. 1990, 62, 708-712.

178. Chaubey, A.; Pande, K. K.; Pandey, M. K.; Singh, V. S.; B. D. Malhotra. Co-immobilization of lactate oxidase and lactate dehydrogenase on conducting polyaniline films. Anal. Chim. Acta 2000, 407, 97-103.

179. Conrath, N.; Gründig, B.; Hüwel, St.; Camman, K. A novel enzyme sensor for the determination of inorganic phosphate. Anal. Chim. Acta 1995, 309, 47-52.

180. DiMeglio, L. A.; White, K. E.; Econs, M. J. Disorders of phosphate metabolism. Endocrinol. Metab. Clin. North. Am. 2000, 29, 591-609.

181. Caruso, F.; Niikura, K.; Furlong, D. N.; Okahata, Y. Assembly of alternating polyelectrolyte and protein multilayer films for immunosensing. Langmuir 1997, 13, 3427-3433.

182. Caruso, F.; Furlong, D N.; Ariga, K.; Ichinose, I.; Kunitake, T. Characterization of polyelectrolyte-protein multilayer films by atomic force microscopy, scanning electron microscopy and Fourier transform infrared reflection-absorption spectroscopy. Langmuir 1998, 14, 4559-4565.

183. Danilowicz, C.; Manrique, J. M. A new self-assembled modified electrode for competitive immunoassay. Electrochem. Commun. 1999, 1, 22-25. 
184. Chen, H.; Lee, M.; Choi, S.; Kim, J. H.; Choi, H. J.; Kim, S. H.; Lee, J.; Koh, K. Comparative study of protein immobilization properties on calixarene monolayers. Sensors 2007, 7, 10911107.

185. Chen, H.; Kim, Y. S.; Lee, J.; Yoon, S. J.; Lim, D. S.; Choi, H. J.; Koh, K. Enhancement of BSA Binding on Au Surfaces by calix[4]bisazacrown Monolayer. Sensors 2007, 7, 2263-2272.

186. Caruso, F.; Rodda, E.; Furlong, D. N. Orientational aspects of antibody immobilization and immunological activity on quartz crystal microbalance electrodes. J. Colloid Interf. Sci. 1996, 178, 104-115.

187. Chatrathi, M. P.; Wang, J.; Collins, G. E. Sandwich electrochemical immunoassay for the detection of Staphylococcal enterotoxin B based on immobilized thiolated antibodies. Biosens. Bioelecton. 2007, 22, 2932-2938.

188. Wang, J. Nanomaterial-based electrochemical biosensors. Analyst 2005, 130, 421-426.

189. Patolsky, F.; Zheng, G.; Liebner, C. M. Nanowire-based biosensors. Anal. Chem. 2006, 78, 4260-4269.

190. Pumera, M.; Sánchez, S.; Ichinose, I.; Tang, J. Electrochemical nanobiosensors. Sensor. Actuat. B-Chem. 2007, 123, 1195-1205.

191. Wang, J. From DNA biosensors to gene chips. Nucleic Acids Res. 2000, 28, 3011-3016.

192. Niemeyer, C. M. Nanoparticles, Proteins, and Nucleic Acids: Biotechnology Meets Materials Science. Angew. Chem. Int. Ed. 2001, 40, 4129-4158.

193. Wanekaya, A. K.; Chen, W.; Myung, N. V.; Mulchandani, Ashok. Nanowire-Based Electrochemical Biosensors. Electroanalysis 2006, 18, 533-550.

194. Dequaire, M.; Degrand, C.; Limoges, B. An electrochemical metalloimmunoassay based on colloidal gold label. Anal. Chem. 2000, 72, 5521-5528.

195. Tang, D.; Yuan, R.; Chai, Y.; Fu, Y.; Dai, J.; Liu, Y.; Zhong, X. New amperometric and potentiometric immunosensors based on gold nanoparticles/tris (2,2'-bipyridyl)cobalt(III) multilayer films for hepatitis B surface antigen determinations. Biosens. Bioelectron. 2005, 21, 539-548.

196. Jena, B. K.; Raj, C. R. Amperometric L-Lactate Biosensor Based on Gold Nanoparticles. Electroanalysis 2007, 19, 816-822.

197. Delvaux, M.; Demoustier-Champagne, S. Immobilisation of glucose oxidase within metallic nanotube arrays for application to enzyme biosensors. Biosens. Bioelectron. 2003, 18, 943-951.

198. Delvaux M., Walcarius A., Demoustier- Champagne, S. Electrocatalytic $\mathrm{H}_{2} \mathrm{O}_{2}$ amperometric detection using gold nanotube electrode ensembles. Anal. Chim. Acta 2004, 525, 221-230.

199. Li, J.; Ng, H. T.; Cassell, A.; Fan, W.; Chen, H.; Ye, Q.; Koehne, J.; Han, J.; Meyyappan, M. Carbon nanotube nanoelectrode array for ultrasensitive DNA detection. Nano Lett. 2003, 3, 597602.

200. Wang, J.; Músame, M.; Lin, Y. Solubilization of Carbon Nanotubes by Nafion toward the Preparation of Amperometric Biosensors. J. Am. Chem. Soc. 2003, 125, 2408-2409.

201. Rubianes, M. D.; Rivas, G. A. Carbon nanotubes paste electrode. Electrochem. Commun. 2003, 5, 689-694.

202. Jain, K. K. Nanotechnolgy in clinical laboratory diagnosis. Clin. Chim. Acta 2005, 358, 37-54. 
203. Duan, C.; Meyerhoff, M. E. Separation-free sandwich enzyme immunoassays using microporous gold electrodes and self-assembled monolayer/immobilized capture antibodies. Anal. Chem. 1994, 66, 1369-1377.

204. Meyerhoff, M. E.; Duan, C.; Meusel, M. Novel nonseparation sandwich-type electrochemical enzyme immunoassay system for detecting marker proteins in undiluted blood. Clin. Chem. 1995, 41, 1378-84.

205. Zhang, F.; Yang, S. H.; Kang, T. Y.; Cha, G. S.; Nam, H.; Meyerhoff, M. E. A rapid competitive binding nonseparation electrochemical enzyme immunoassay (NEEIA) test strip for microcystin-LR (MCLR) determination. Biosens. Bioelectron. 2007, 22, 1419-1425.

206. Zhang, F.; Cho, S. S.; Yang, S. H.; Seo, S. S.; Cha, G. Sig; Nam, H. Gold Nanoparticle-Based Mediatorless Biosensor Prepared on Microporous Electrode. Electroanalysis 2006, 18, 217-22.

207. Patolsky, F.; Wizemann, Y.; Willner J. Long-range electrical contacting of redox enzymes by SWCNT connectors. Angew. Chem. Int. Ed. 2004, 43, 2113-2117.

208. Willner, B.; Katz, E.; Willner, I. Electrical contacting of redox proteins by nanotechnological means. Curr. Opin. Biotech. 2006,17, 589-596.

209. Kerman, K.; Nagatani, N.; Chikae, M.; Yuhi, T.; Takamura, Y.; Tamiya. E. Label-free electrochemical immunoassay for the detection of human chorionic gonadotropin hormone. Anal. Chem. 2006, 78, 5612-5616.

210. Vestergaard, M.; Kerman, K.; Tamiya E. An overview of Label-free Electrochemical Protein Sensors. Sensors 2007, 7,3442-3458.

211. Katakis, I.; Mir M. Towards a fast-responding, label-free electrochemical DNA biosensor. Ana. Bioanal. Chem. 2005, 381, 1033-1035.

212. Wang J.; Kawde, A. Pencil-based renewable biosensor for label-free electrochemical detection of DNA hybridization. Anal. Chim. Acta 2001, 431, 219-224.

213. Kerman, K.; Morita, Y.; Takamura, Y.; Tamiya, E. Label-free electrochemical detection of DNA hybridization on gold electrode. Electrochem. Commun. 2003, 5, 887-891.

214. Takata, M.; Kerman, K.; Nagataki, N.; Konaka, H.; Namiki, M.; Tamiya, E. Label-free bioelectronic immunoassy for the detection of human telomerase reverse transcriptase in urine. J. Electroanal. Chem. 2006, 596, 109-116.

215. Janasek, D.; Franzke, J.; Manz, A. Scaling and the design of miniaturized chemical-analysis systems. Nature 2006, 442, 374-380.

216. Schabmueller, C. G. J.; Loppow, D.; Piechotta, G.; Schutze, B.; Albers, J.; Hintsche, R. Micromachined sensor for lactate monitoring in saliva. Biosens. Bioelectron. 2006, 21, 17701776.

217. de Mello, A. J.; Beard, N. Dealing with "real" samples: sample pre-treatmment in mycrofluidic systems. Lab Chip 2003, 3, 11N-19N.

218. Wang, J.; Chatrathi, M. P.; Ibanez, A. Glucose biochip: dual analyte response in connection to two pre-column enzymatic reactions. Analyst 2001, 126, 1203-1206.

219. Wang, J.; Chatrathi, M. P.; Tian, B. Microseparation chips for performing multienzymatic dehydrogenase/oxidase assays: simultaneous electrochemical measurement of ethanol and glucose. Anal. Chem. 2001, 73, 1296-1300 
220. Wang, Y. C.; Stevens, A. L.; Han, J. Million-fold Preconcentration of Proteins and Peptides by Nanofluidic Filter. Anal. Chem. 2005, 77, 4293-4299.

221. Wang, J.; Ibanez, A.; Chatrathi, M. P.; Escarpa, A. Electrochemical enzyme immunoassays on microchip platforms. Anal. Chem. 2001, 73, 5323-5327.

222. Goral, V. N.; Zaytseva, N. V.; Baeumner, A. J. Electrochemical microfluidic biosensor for the detection of nucleic acid sequences. Lab Chip 2006, 6, 414-421.

223. Soper, S. A.; Brown, K.; Ellington, A.; Frazier, B.; Garcia-Manero, G.; Gau, V.; Gutman, S. I.; Hayes, D. F.; Korte, B.; Landers, J. L.; Larson, D.; Ligler, F.; Majumdar, A.; Mascini, M.; Nolte, D.; Rosenzweig, Z.; Wang, J.; Wilson, D. Point-of-care biosensor systems for cancer diagnostics/prognostics. Biosens. Bioelectron. 2006, 21, 1932-42.

224. Rasooly, A.; Jacobson, J. Development of biosensors for cancer clinical testing. Biosens. Bioelectron. 2006, 21, 1851-1858.

225. Petrlova, J.; Potesil, D.; Zehnalek, J.; Sures, B.; Adam, V.; Trnkova, L.; Kizek, R. Cisplatin electrochemical biosensor. Electrochim. Acta 2006, 51, 5169-5173.

226. Daniels, J. S.; Pourmand, N. Label-Free Impedance Biosensors: Opportunities and Challenges. Electroanalysis 2007, 19, 1239-1257.

227. Barrettino, D. Design considerations and recent advances in CMOS-based microsystems for point-of-care clinical diagnostics. ISCAS 2006. Proc. IEEE Int. Symp. 2006, 4359-4362.

228. Tüdốs, A. J.; Besselink, G. A. J.; Schasfoort, R. B. M. Trends in miniaturized total analysis systems for point-of-care testing in clinical chemistry. Lab Chip 2001, 1, 83-95.

229. Yager, P.; Edwards, T.; Fu, E.; Helton, K.; Nelson, K.; Tam, M. R.; Weigl, B H. Microfluidic diagnostic technologies for global public health. Nature 2006, 442, 412-418.

C) 2008 by MDPI (http://www.mdpi.org). Reproduction is permitted for noncommercial purposes. 